Int. J. Dev. Biol. 56: 447-462 (2012)

doi: $10.1387 / \mathrm{ijdb} .113483 \mathrm{hm}$

\title{
Modeling pattern formation in hydra: a route to understanding essential steps in development
}

\author{
HANS MEINHARDT* \\ Max-Planck-Institut für Entwicklungsbiologie, Tübingen, Germany
}

\begin{abstract}
Modeling of pattern formation in hydra has revealed basic mechanisms that underlie the reproducible generation of complex and self-regulating patterns. Organizing regions can be generated by a local self-enhancing reaction that is coupled with an inhibitory effect of longer range. Such reactions enable pattern formation even in an initially almost homogeneous assembly of cells. A long-ranging feedback of the organizer onto the competence to perform the pattern-forming reaction stabilizes the polar axial pattern during growth and allows for regeneration with preserved polarity. Hypostome formation is assumed to be under the control of two positive feedback loops in which Wnt3 is a common element. In addition to the well-established loop employing $\beta$-catenin, a second cell-local loop is involved, possibly with Brachyury as an additional component. This model accounts for the different expression patterns of $\beta$-catenin and Wnt3. Wnt molecules are proposed to play a dual role, functioning as activators and, after processing, as inhibitors. Since Wnt genes code for complete pattern-forming systems, gene duplication and diversification lead to a family of genes whose expression regions have a precise relation to each other. Tentacle formation is an example of positioning a second pattern-forming system by medium-ranging activation and local exclusion exerted by the primary system. A model for bud formation suggests that a transient prebud signal is involved that initiates the formation of the foot of the bud, close to the normal foot, as well as close to the bud tip. Many dynamic regulations, as observed in classical and molecular observations, are reproduced in computer simulations. A case is made that hydra can be regarded as a living fossil, documenting an evolutionary early axis formation before trunk formation and bilaterality were invented. Animated simulations are available in the supplementary information accompanying this paper.
\end{abstract}

KEY WORDS: pattern formation, hydra, Wnt, activator-inhibitor, evolution body axes, budding, tentacle

\section{Introduction}

Central in developmental biology is the question how different structures can form at different positions although the genetic information is the same in all cells. Several features make the freshwater polyp hydra and its relatives to most convenient model organisms. Hydra is famous for it's almost unlimited capability to regenerate, a feature already discovered more then 250 years ago (Trembley, 1744), (reviewed by Gierer, 1977; Bode, 2003; Holstein et al., 2003, Bosch, 2007; Galliot and Ghila, 2010). Even after dissociation into individual cells and re-aggregation, clumps of hydra cells can re-form viable organisms (Gierer et al., 1972; see Fig. 1 in Gierer, 2012), testifying that pattern formation can be a self-organizing process that does not require initial asymmetries or localized determinants.

Pattern formation in hydra is most interesting for several reasons. With its single axis the pattern is relatively simple, but complex enough to study basic problems of animal development. The oral opening of the gastric column, the so-called hypostome, is an organizing region and historically the first organizing region discovered (Browne, 1909; Lenhoff 1991; Bode, 2012). Small tissue fragments from the hypostome, when transplanted into the body column of another animal, can induce a second axis with a new head. Hydra reproduces mostly by budding, a process that requires the generation of new organizing regions along the body column. Tentacle formation near the hypostome allows to study of how structures are

Abbreviations used in this paper: Dkk, Dickkopf; Tcf, T-cell factor.

\footnotetext{
*Address correspondence to: Hans Meinhardt. Max-Planck-Institut für Entwicklungsbiologie, Spemannstr. 35, D-72076Tübingen, Germany.

Tel.: +49-7071-601-399. e-mail: hans.meinhardt@tuebingen.mpg.de - web: http://www.eb.tuebingen.mpg.de/meinhardt
}

Supplementary Material (movies, equations and parameters) for this paper is available at: http://dx.doi.org/10.1387/ijdb.113483hm

Final, author-corrected PDF published online: 24 January 2012

ISSN: Online 1696-3547, Print 0214-6282

(C) 2012 UBC Press

Printed in Spain 
formed close to an organizer, maintaining nevertheless a certain distance. In contrast, hypostome and foot formation at antipodal positions - called oral and aboral poles - offers an inroad to study how structures are generated at largest-possible distance over a remarkable range of size. While in many other systems pattern regulation is restricted to early phases of development, in coelenterates this capability is maintained permanently.

Pattern regulation indicates that a communication exists between different parts, such that the removal of some parts is detected in the remaining organism and the missing structures become replaced. What types of communication allow pattern formation and regeneration to occur? In addition to the classical perturbation and transplantation experiments, recent molecular approaches provided substantial new information. However, the mechanism of pattern formation can be inferred directly neither from observed regulatory features nor from the detection of local gene activations. Earlier or later one has to make hypotheses about how the underlying mechanisms work. Since pattern formation is expected to depend of several interlinked positive and negative feedback loops, it is impossible to deduce the crucial interactions by intuition. By formulating the hypothesis in a mathematical way and simulate the expected patterning processes on a computer, it is possible to check whether a hypothesis is able to account for

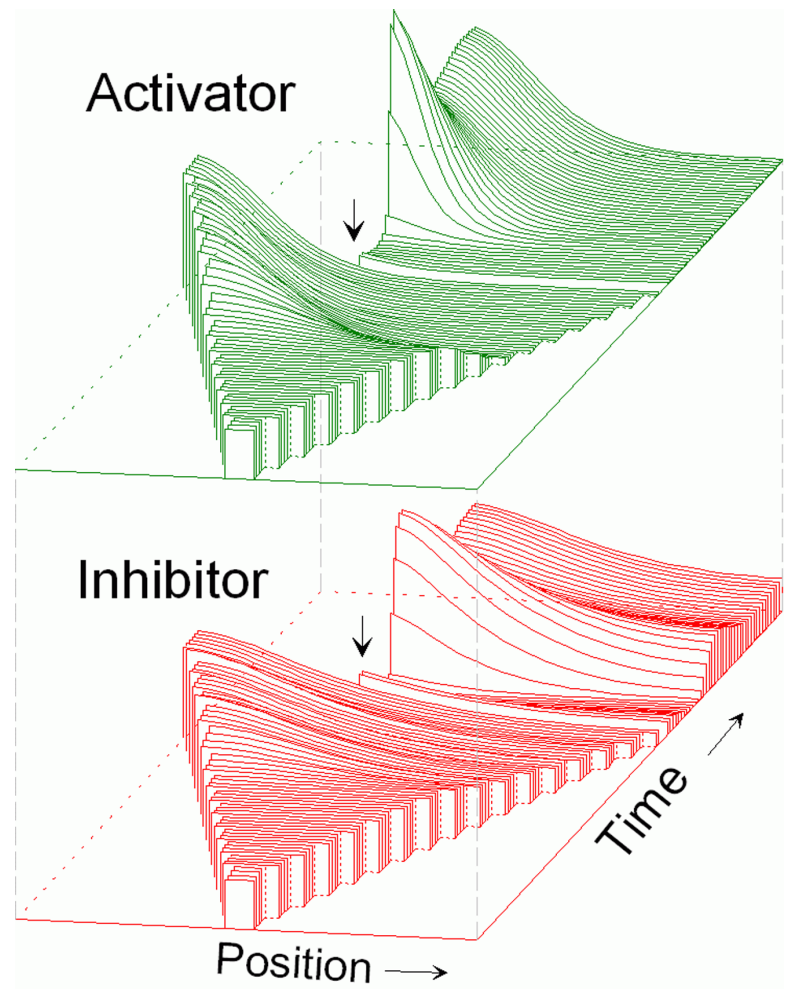

Fig. 1. Formation of a polar pattern by an activator-inhibitor reaction in a growing field. A pattern forms when a critical size (the range of activator) is exceeded. At the critical size the maximum can appear only at one boundary and can remain there upon further growth (see Fig. 6). The activator maximum is assumed to act as an organizing region. Thus, the model accounts for the formation of polar concentration profiles, even in an initially near-homogeneous situation. After removal of the activated region (arrows), the remnant inhibitor decays und a new maximum is formed the basic process in the regeneration of an organizing region. Assumed are linearly arranged cells; concentrations are plotted as function of time. the observations. Mathematically-based models will be discussed that describe the regeneration and transplantation experiments in detail. These minimum models provide an answer of what is at least required to perform a particular task. The basic mechanism was proposed before signalling molecules were known (Gierer and Meinhardt, 1972), using the classical experiments of axial grafts and regeneration as a first test. It turned out that these models are also able to account for many of the more recent observations made on the molecular level.

Coelenterates are at the base of the metazoan evolutionary tree. Essential for their axial organization is the Wnt pathway (Hobmayer et al., 2000; Broun et al., 2005; Kusserow et al., 2005; Bosch 2007; Lengfeld et al., 2009; Plickert et al., 2006; Gee et al., 2010; Duffy et al., 2010). A comparison of the expression patterns of Wnt, Brachyury and several other genes in hydra and higher organisms suggests that the head of the hydra, in contrast to its usual naming, represents the most posterior and the foot the most anterior structure (Meinhardt, 2002). At the end of this paper I will briefly discuss models for axes formation in higher organisms that were inspired by hydra. They shed light, for instance, on the transition from radial-symmetric to bilateral-symmetric body plans including the deep split between protostomia and deuterostomia.

\section{The driving force in pattern formation: local self-en- hancement and long-range inhibition}

Pattern formation is possible if and only if a short-ranging selfenhancing reaction is antagonized by an inhibitory reaction of longer range (Gierer and Meinhardt, 1972, Gierer, 1977; Meinhardt, $1982 ; 2008)$; (see also Gierer, this volume). These two components together allow for a situation in which a homogeneous distribution of both substances is instable. A straightforward realization of our general scheme consists of an activator whose autocatalytic activation is antagonized by a long-ranging inhibitor that is produced under activator control. Even random fluctuations are sufficient to initiate pattern formation (Fig. 1). A minute increase of the activator will increase further due to the self-enhancement. The concomitantly elevated inhibitor production cannot compensate this increase due to its rapid diffusion, causing a de-activation in the surroundings of the incipient maximum. A patterned stable steady state will be reached when the activation in an emerging maximum is balanced by the surrounding cloud of inhibition (Fig. 1). The mechanism is compatible with that proposed by Alan Turing in his pioneering paper, which demonstrated that reaction-diffusion systems are capable of generating concentration patterns (Turing, 1952). However, the crucial conditions mentioned above, local self-enhancement and long-range inhibition, are not inherent in his paper. By knowing this condition we were able to recognize pattern-forming capabilities in more complex interactions and to introduce non-linear interactions that are indispensable to formulate molecularly realistic interactions leading to stable, reproducible patterns. As discussed elsewhere (Meinhardt, 1982), pattern formation in the inorganic world such as formation of sand dunes, patterns of erosion, lightning and many pattern in social interactions are based on the same principle.

\section{Pattern regulation and regeneration}

Long before the advent of molecular developmental genetics, insights into rules on which pattern formation is based have been 
derived from perturbation of the normal steady state pattern, for instance by transplantation of tissue to ectopic positions or by tissue removal. It was a first test of our general theory that it was able account for the observed pattern regulations.

Upon removal of the organizing region, i.e., the region in which both the activator and the inhibitor is produced, the remnant inhibitor decays in the remaining tissue and a new activator maximum can be triggered; the organizing region becomes restored (Fig. 1). In simple patterning systems, the polarity needs not to be maintained during regeneration. The stolons of colonial marine hydroids are an interesting model system (Fig. 2). In contrast, regeneration in hydra or planarians occurs always by maintaining the polarity. The reason will be discussed further below.

Classical experiments have revealed that the probability for a head-derived tissue to induce a new axis upon transplantation into the body column increases with increasing distance from the existing head, suggesting that a long-ranging inhibition spreads from the head. The tissue is, however not uniform. Tissue from the hypostome has the highest chance to induce a new head. The probability declines if the tissue is derived from regions more remote from the head (Wilby and Webster, 1970a,b; Wolpert et al., 1971; Hicklin et al., 1973; (reviewed in Shostak, 1973; Shimizu, 2012; this issue). Some basic observations and their explanation in terms of the early model are given in Fig. 3.

In an ingenious experiment using cell aggregates, the parameters of the hypostomal pattern-forming reaction were determined (Technau et al., 2000). By head removal, a hydra was forced to regenerate. Aggregates were prepared from labeled cells derived from the regenerating tip and mixed with unlabelled cells obtained from untreated body columns. Expected was that the pre-activated cells have a higher chance to form newly activated regions in the aggregate. Observed was that clusters of 5-15 cells were necessary for an elevated probability to trigger. In terms of our model, this provides a measure for the range of the activator diffusion. Smaller clusters loose too rapidly the activator excess. To determine the range of inhibition, they used differently-stained pre-activated clusters and observed the minimum distance that two clusters must have without repressing each other. They found a distance of 800 to $900 \mu \mathrm{m}$ whereby a larger cluster has a much higher chance to repress a smaller one. These findings are in full agreement with our model. The differences in the ranges of the activation and the inhibition observed in this experiment are fully compatible with the 15-fold difference in the diffusion rates we assumed in our first simulation of hydra patterning (Gierer and Meinhardt, 1972; Fig. 3).

\section{Known components involved in pattern-forming reac- tions}

At the time this mechanism was proposed, possible molecular realizations where virtually unknown. Meanwhile several interactions were discovered that exhibits the basic function of autocatalytic activation and long range inhibition (Meinhardt, 2008). An example is the Nodal/Lefty2 interaction. In vertebrates it is involved in mesoderm and midline formation; at later stages in the left/right patterning (Bisgrove et al., 1999; Chen and Schier, 2002; Nakamura et al., 2006). In sea urchins Nodal/Lefty2 is involved

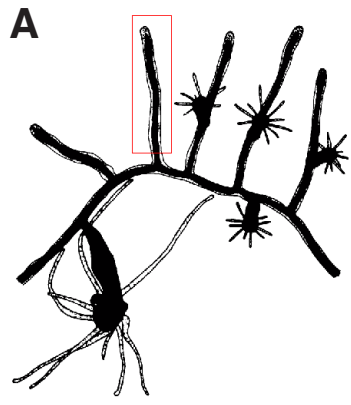

D
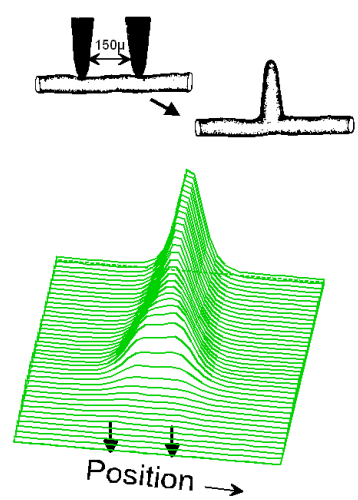

B

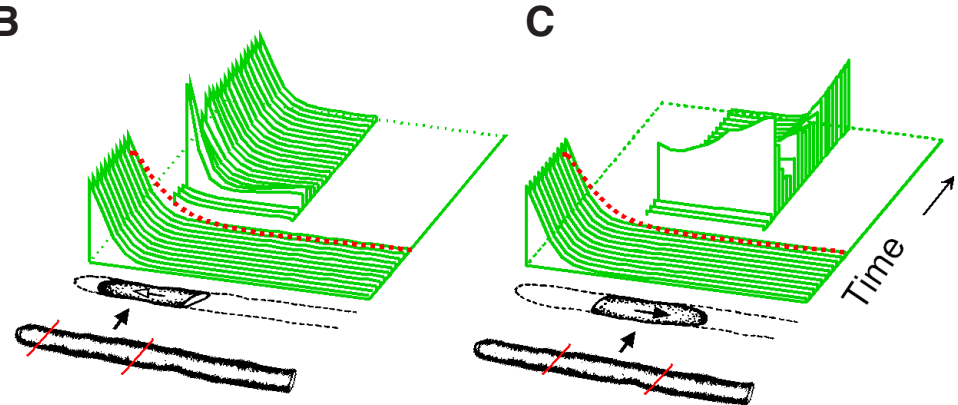

E
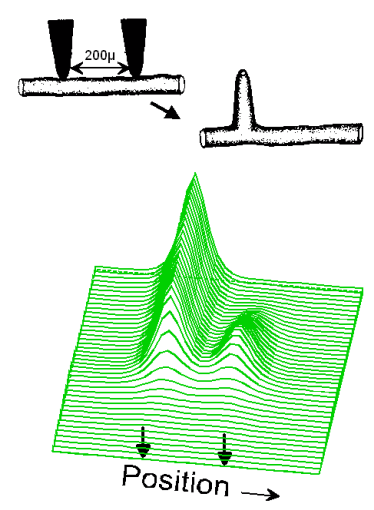

$\mathbf{F}$
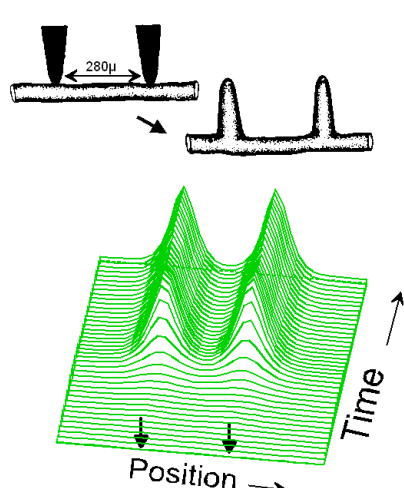

Fig. 2. Experiments with stolons of the marine hydroid Eirene viridulaillustrates essential regulatory features of a simple patternforming reaction lexperiments by Müller and Plickert, 1982; Plickert, 1980; simulations from Meinhardt, 1982). (A) The individual polyps are interconnected by a network of stolons. (B) A near-tip fragment regenerates with normal polarity. Model: some activation from the original maximum is included in the fragment and acts as a trigger. (C) In a fragment derived from a more distant position, regeneration can occur with reversed polarity. Model: the inhibitor (red) remaining in the stolon is lowest at the antipodal side, providing and advantage at this position. A similar polarity reversal during regeneration has been observed in sea urchins (Hörstadius and Wolsky, 1936). (D-F) Mechanical stimulation of a stolon can trigger branch formation, repeating the formation of a connection when a growing stolon touches an existing stolon. (D) If the distance between two stimuli is small, only a single branch is formed between the two stimuli. Model: the two activations merge. (E) At somewhat larger distances, also one branch forms, but this occurs at the position where one of the stimuli was given. Model: one peak is downregulated while the other survives. (F) At even larger distances two branches are formed. Model: the long-range inhibition is too weak; neither peak can down-regulate the other. The mechanical trigger is assumed to lead to a local temporary loss of some inhibition (arrows) that triggers the activation. The final pattern is the result of the self-organizing interaction. 
A

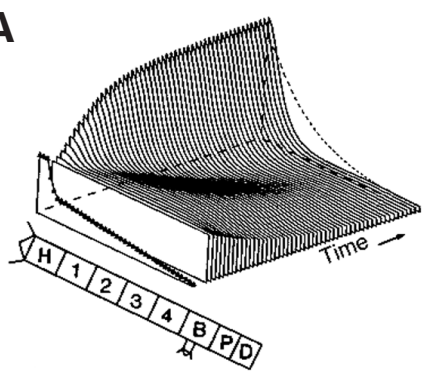

B

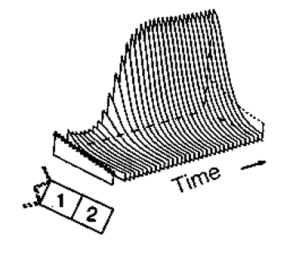

E
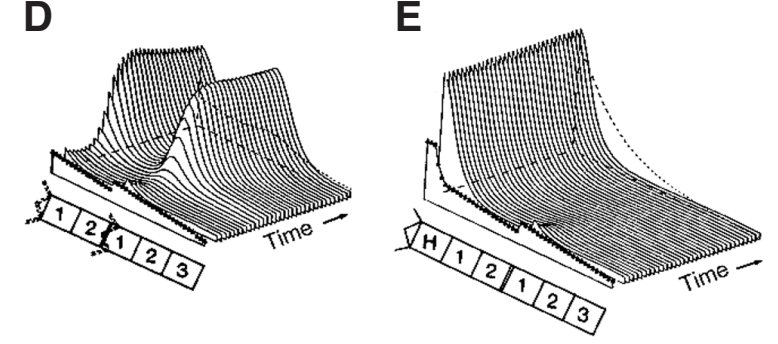

H

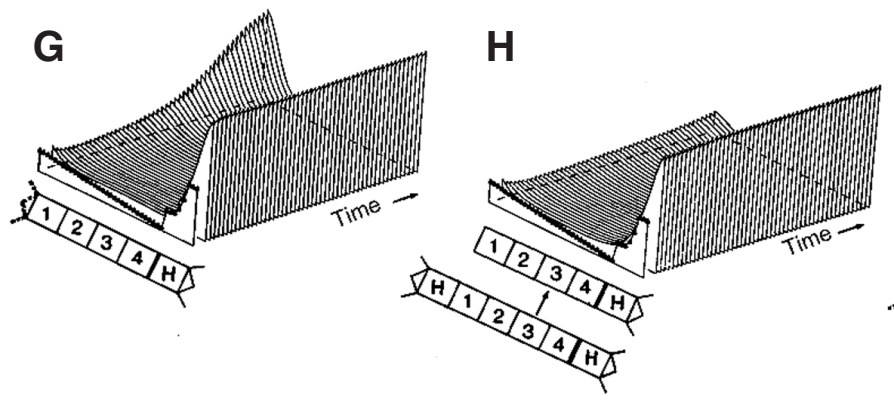

C

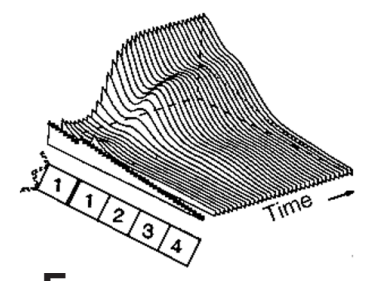

F

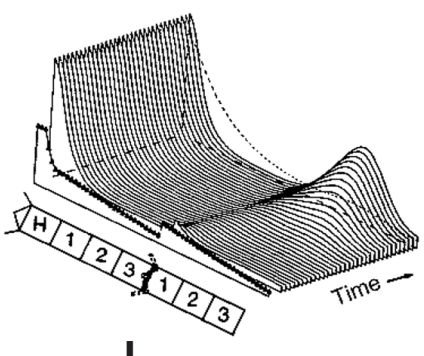

I

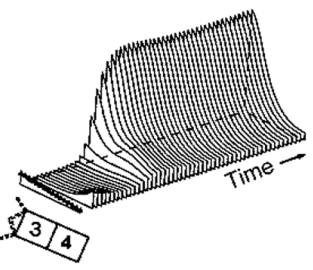

ment, the original head is removed not earlier than 6 hours after implantation of the second head, iffuse through the animal. After removal of the original head, its regeneration is frequently suppressed. (I) A fragment of such a hydra with apparently

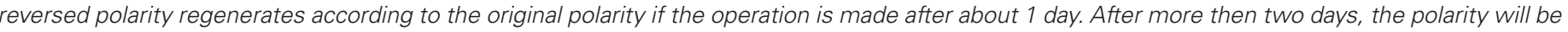
permanently reverted. (For experiments see Wilby and Webster, 1970a,b; Wolpert et al., 1971; Hicklin et al., 1973).

the formation of the oral field (Duboc et al., 2004). Nodal is a secreted factor that positively feeds back on its own production. For signaling, Nodal has to form dimers, in agreement with the theoretically expected non-linearity of the autocatalysis. Lefty2 is under the same control as Nodal and acts as an inhibitor. In agreement with the theoretical expectation for an inhibitor, Lefty2 diffuses much faster than Nodal (Sakuma et al., 2002; Marjoram and Wright, 2011).

The activation of $F G F$ at the aboral pole of the planula larva of the sea anemone Nematostella is another example (Rentzsch et al., 2008). NvFGFa1 activates its own expression and that of the antagonist NvFGFa2; both using the same receptor. Most remarkably, the receptor itself seems to be part of the feedback loops and become locally upregulated.

The self-enhancement needs not to be direct. For instance, much of the pattern regulation observed in the famous Spemann organizer can be explained under the assumption that the mutual inhibition of the two key components, Chordin and Bmp, provide as a system the necessary self-enhancement. For instance, an elevation of Chordin leads to a decline of BMP, causing a further increase in Chordin, as if Chordin would be autocatalytic. The Anti-Dorsalizing-Morphogenetic-Protein, ADMP, acts as the longer-ranging inhibitor by antagonizing the inhibitory action of Chordin on BMP (reviewed in De Robertis 2009, Niehrs, 2004; for modeling see Meinhardt, 2006, 2008). As discussed at the end of the paper, the ancestral Wnt-based hydra-type organizer is the precondition to form the Chordin-based Spemann organizer on the opening of the gastric cavity, the blastopore.

Most remarkable is that in all these systems the inhibitor interrupts the self-enhancement by blocking the receptor that is required for activation. Thus, the inhibitory action occurs outside of the cell. Transmission of an inhibitory signal into the cell would require time and this may render the system susceptible for becoming oscillating (Lee et al., 2010). With blocking the self-activation in the extracellular space, nature found an elegant way to keep the pattern-forming system stable.

\section{Wnt molecules: both activators and inhibitors?}

As mentioned, essential for the axial organization of coelenterates is the Wnt pathway. Despite the fact that so much is known about this pathway, there is still a substantial gap in our understanding how pattern formation is accomplished by the known components. The predicted autoregulatory component has been recently confirmed. The regulatory part of the HyWnt3a gene contains an element that employs $\beta$-catenin and Tcffor the autoregulatory feedback (Nakamura et al., 2011).

In contrast, the molecular nature of the long-ranging inhibition 
is still elusive. Dickkopf (Dkk) is a diffusible Wnt antagonist. In hydra, $D k k 1 / 2 / 4$ has a graded distribution over the body column, excluding, however, the region where $\beta$-cateninis expressed (Augustin et al., 2006; Guder et al., 2006b; Fig. 4). This rules out that $D k k$ is the inhibitor in terms of our theory since then a high Dkk expression in the head region would be expected. Likewise, the general downregulation of $D k k$ upon ectopic $\beta$-catenin activation is also incompatible with a role of $D k k$ as the inhibitor.

Wnt molecules are known to be packed into different types of vesicles that can have different ranges (reviewed in Lorenowicz and Korswagen, 2009; Port and Basler, 2010). Based on several observations in different systems a two-gradient model has been proposed (Bartscherer and Boutros, 2008), according to which Wntmolecules are first secreted on the apical side of an epithelial layer. Due to the tethering with lipids, their spread is of short range. Transcytosis of Wntmolecules leads to association with lipoprotein particles making these processed Wnt molecules more mobile. Secretion may be restricted to basolateral cell surfaces. In hydra, the formation and action of the two types of Wnt's may involve an interplay between the two cell sheets. So far it is unclear whether the two varieties have different functions. In terms of the model we expect that the short-ranging lipid-anchored Wnt molecules acts in the autoregulatory loop. In contrast, Wnt3 molecules that have a long range due to their association with lipoprotein particles are expected to be involved in the inhibition. Since no separate genes are expected that code for long-ranging Wnt-inhibitors, the model provides an explanation why such genes were notoriously untraceable, also, e.g., in planarians (Gurley et al., 2010). In such a "conversion" mechanism the activator and the inhibitor are naturally produced at the same position, as predicted.

The long-ranging Wnt3 component may trigger Dkk production. By binding to the Wnt-receptor complex, Dkk can block the reception of the Wnt signal at the cell surface (Bafico et al., 2001; Mao et al., 2001; Niehrs, 2006). Thus, Dkk triggered by the long-ranging $W n t$, may interrupt the short-ranging autoregulatory Wnt-loop. The graded expression of $D k k$ that extends up to the budding region would be an indicator for long-ranging Wnt gradient that is not directly measurable thus far. In agreement, shortly after bud initiation, Dkk expression is up-regulated in the vicinity of the new bud (Augustin et al., 2006; Fig. 4G), thought to be caused by the long-ranging inhibitory Wntmolecules that spreads from the emerging bud. However, the Dkk pathway cannot be the only mode of the inhibitory action since $D k k$ is absent in the head region where the self-enhancement also has to be antagonized.

$\beta$-catenin has a graded distribution. Since $\beta$-catenin is not secreted, the graded distribution cannot result from diffusion. According to the model, since both $\beta$-catenin and the slowly-diffusing Wnt-molecules act in the same positive loop, the graded $\beta$-catenin distribution is an indictor for the distribution of the slowly diffusing activating Wnt molecules. The mutual exclusion of $D k k$ and
A
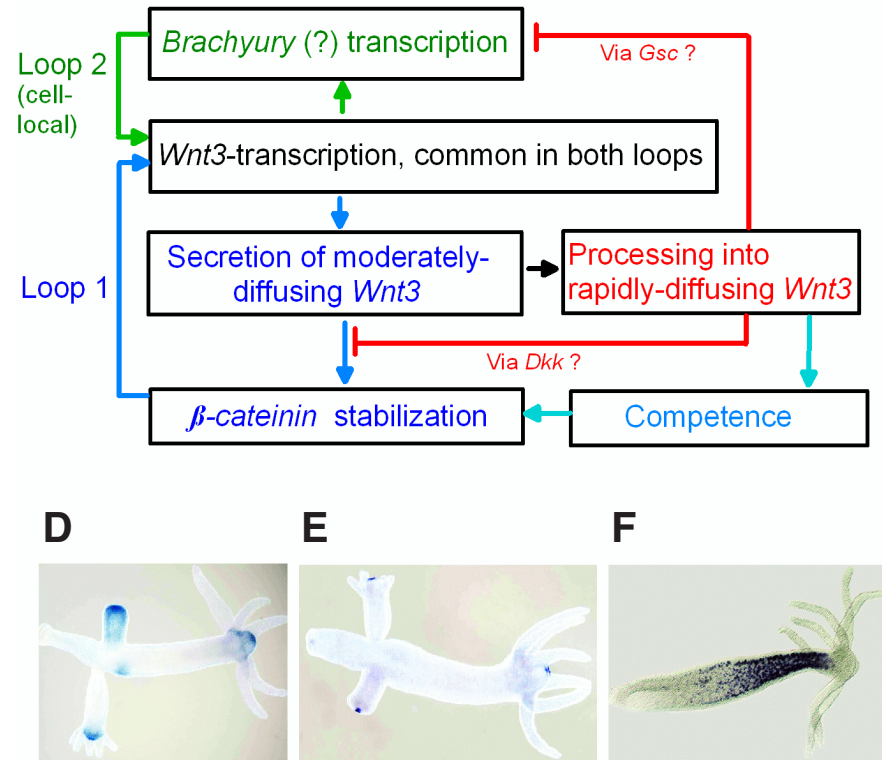

$E$

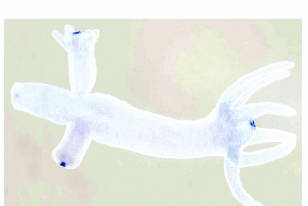

$\mathbf{F}$

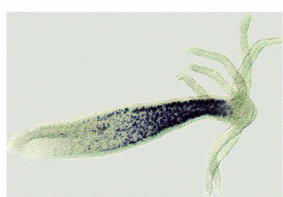

B

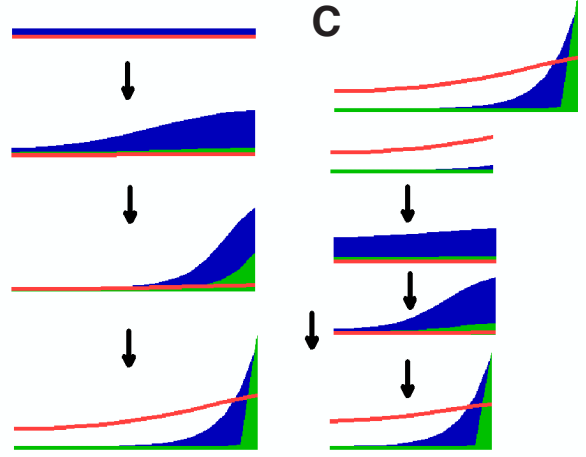

G

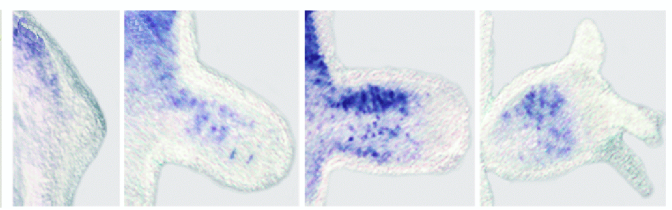

Fig. 4. Model for the different expression patterns of $\boldsymbol{\beta}$-catenin and Wnt3 in the patterning of the hypostome. (A) The assumed reaction scheme. In addition to the standard loop that employs Wnt3 and $\beta$-catenin (blue, loop 1) a second cell-local loop is assumed that is based on Wnt3 and possibly Brachyury transcription (green; loop 2). The long-ranging inhibition required for both loops is assumed to result from Wnt3 molecules that diffuse much faster (red) due to association with lipid particles (Bartscherer and Boutros, 2008). (B) Simulation of primary patterning: the second loop Wnt3; green) can be triggered only if the first loop ( $\beta$-catenin, blue) has achieved a certain level. Since the components of the second loop do not diffuse, the Wnt3 peak is sharp. (C) Regeneration: the sharp Wnt3 peak appears with some delay, as observed. (D-G) Observed expression patterns of Wnt3 (D), $\beta$-catenin $/ \operatorname{cf}$ (E) (Hobmayer et al., 2000) and Dkk1/2/4 (Augustin et al., 2006) (F, G); both expressions locally exclude each other. The graded $\beta$-catenin distribution is assumed to result from the slowly diffusing Wnt3 molecules and visualizes their distribution. In contrast, the graded Dkk1/2/4 expression that extends into the budding zone is assumed to result from an activation by the long-ranging Wnt3 molecules, providing in this way an indicator for their distribution that is otherwise not yet observable. (G) In agreement with this view, as soon as a new bud is formed, new Dkk expression appears in the surrounding, assumed to result from the newly-produced diffusible Wnt3. For details of the simulation, see Supplementary Material. Images $(D, E)$ kindly supplied by Bert Hobmayer and Thomas Holstein (see Hobmayer et al., 2000); and images (F, G) by Thomas Bosch and René Augustin (see Augustin et al., 2006), with permission of "Nature" and "Dev. Biol." 
$\beta$-catenin may contribute to the shaping of the $\beta$-catenin gradient. The proposed double function of a Wnt gene is not as unusual as it may appear at a first glance. The corresponding gene in Drosophila, wingless, has a similar double function. For the non-local inhibitory function, wingless is transported in vesicles to the posterior-adjacent cells where it is required to maintain the engrailed activity. engrailed expression, however, excludes locally wingless expression. Thus, wingless contributes to the restriction of its expression by activation engrailed (reviewed by Ingham and Hidalgo, 1993). Involved in the local positive feedback loop of wingless is the forkhead domain transcription factor sloppy paired (Lee and Frasch, 2000). This component also has a counterpart in hydra that shows an expression pattern similar to $\beta$-catenin (Martinez et al., 1997), suggesting that the activation-inhibition double function of Wnt-molecules is an evolutionary conserved feature.

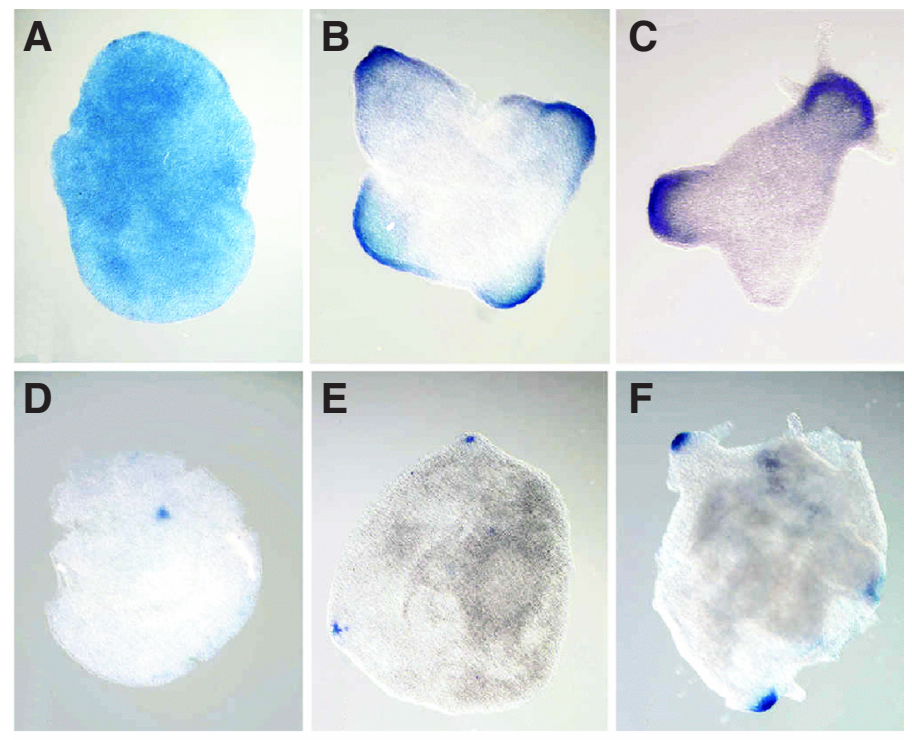

G

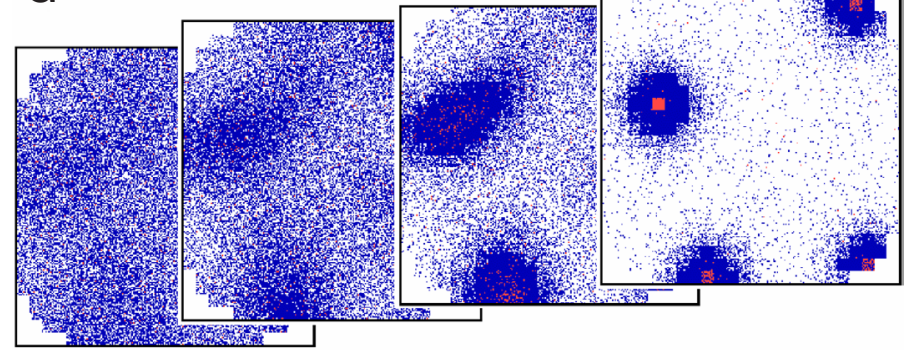

Fig. 5. Different expression patterns of Tcf / $\beta$-catenin and Wnt3 in aggregates (Hobmayer et al., 2000) and their simulations. (A-C) Tcf (and $\beta$-catenin) shows initially a more cloudy distribution that sharpens later on. (D-F) In contrast, Wnt3 appears directly as sharp peaks (as Brachyury does, see Technau and Bode, 1999). (G) Simulation: assumed are two positive loops; the first loop involves the classical reaction including $\beta$-catenin (blue); the second is cell-local and includes Wnt3-transcription as common element (red, see also Fig. 4); (Meinhardt, 2012). The characteristic features are reproduced. According to the model, activation of $\mathrm{Wnt} 3$ is also involved in the primary cloudy $\beta$-catenin activation. Only the level is much lower than that achieved after the trigger of the cell-local loop. (Figures A-F kindly supplied by Bert Hobmayer and Thomas Holstein, see Hobmayer et al., 2000; with permission of "Nature").

\section{The Wnt code}

In hydra and Nematostella, different Wnt genes have been found to be expressed at early stages in displaced but partially overlapping regions, a pattern proposed to represent a Wntcode for supplying positional information (Guder et al., 2006a; Kusserow et al., 2005). Similar observations have been made in Nematodes (Harterink et al., 2011) and planarians (Gurley et al., 2010). In terms of the model, due to the double function of Wnt, any gene duplication establishes a new and complete pattern-forming system, each with an activator and an inhibitor. If, due to subsequent modifications, the different activators interfere, maxima will preferentially appear at non-overlapping positions. In contrast, if the inhibitor of one system undermines the inhibition of a second system, the first system has in fact an activating influence on the second. Both effects together leads to an expression pattern in a controlled neighborhood, as observed. A theoretical framework for the generation of a positional code by mutual long-range activation and local exclusion of several feedback loops has been predicted long time ago (Meinhardt and Gierer, 1980; Meinhardt, 1982, Meinhardt, 2008). Individual cells can move through these zones while the zones maintain their position, a feature of obvious importance for hydra patterning. The initiation of tentacles in relation to the hypostome will be discussed further below as an example.

\section{Two positive feedback loops in the generation of the primary organizer}

$\beta$-catenin and Wnt3 are usually assumed to be part of a single positive feedback loop (Holstein et al., 2003; Nakamura et al., 2011), and yet, the expression patterns of both genes are remarkably different (Figs. 4, 5). In aggregates, $\beta$-catenin and Tcfare first expressed in a more cloudy pattern that sharpen subsequently into distinct but smooth peaks. They mark the regions where later new hypostomes are formed (Hobmayer et al., 2000). This pattern corresponds to the theoretically expected dynamics. In contrast, Wnt3 (and Brachyury) appears directly as sharp peaks. Likewise during regeneration and budding $\beta$-catenin has initially a broader distribution that sharpens in the course of time while Wnt and Brachyury appear as sharp spots that enlarge (Technau and Bode, 1999; Hobmayer et al., 2000).

These different expression patterns suggest that two positive feedback loops are at work that differ in the range of the molecules involved. The following still hypothetical network of interactions displays many of the observed patterns and their regulation (Fig. 4A). A first loop employs the conventional ingredients: local Wnt3 transcription leads to the secretion of short-ranging Wnt3 molecules into the intracellular space. Their signaling via Wnt receptors leads to $\beta$-catenin -stabilization that stimulates Wnt3 transcription. In this way, $\beta$-catenin, although it is not secreted, assumes a graded distribution since it is in a loop with the secreted $W n t$. The extension of $\beta$-catenin expression, in turn, is restricted by the antagonistic effect of the more diffusible Wnt3 molecules that results from processing into a more rapidly diffusing variant, e.g., by tethering to lipid particles as discussed above.

The second feedback loop is assumed to be cell-local and also employs Wnt3 as one of its components, but only a non-secreted part of the pathway. A loop of Wnt3 and Brachyury is a possible 
candidate, although Brachyury seems to have a somewhat broader expression pattern and Wnt3 and Brachyury behaves different upon treatment with Alsterpaullone (Gee et al., 2010). A Wnt-Brachyury loop is also known to be involved in posterior elongation in higher organisms (Martin and Kimelman, 2009). This cell-local Wnt-loop is assumed to require a relatively high activity of the first $\beta$-catenin-containing loop for triggering. Thus, the trigger of the second loop occurs only after $\beta$-catenin of first loop has reached a certain level. This accounts for somewhat delayed trigger of the sharp Wnt-peaks in aggregates (Fig. 5). The antagonistic reaction can work via the very same putative longranging Wnt molecules already inferred for antagonizing the first loop. Different intermediates such as Goosecoidare conceivable. An important feature is that Wnt3 participates in both loops, a cross-activation that is crucial for the correct description of cer-
A
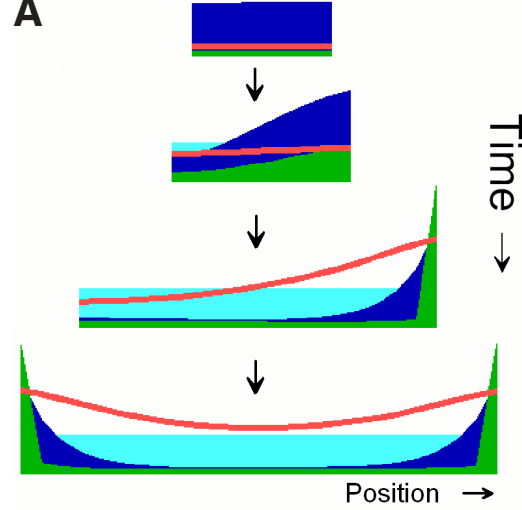

B

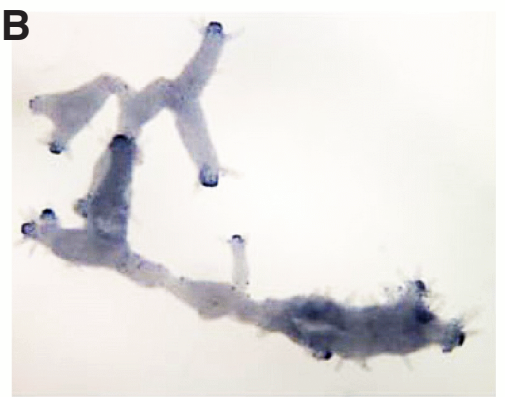

C

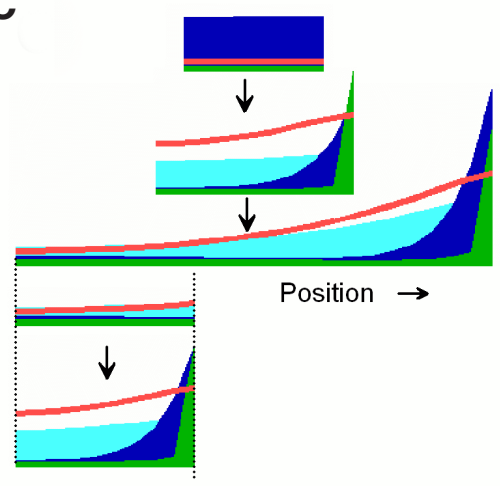

D

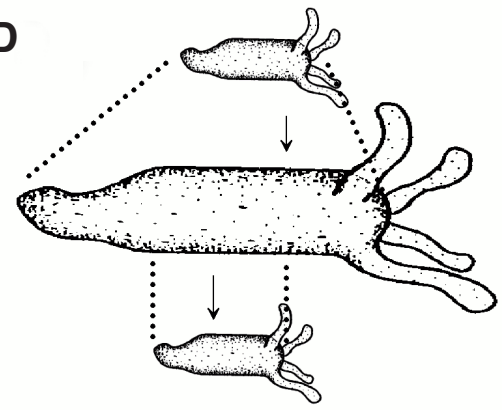

Fig. 6. The role of a graded competence - the ability to perform the pattern-forming reaction. (A) If all cells are equally competent to generate the head signal, upon growth cells can escape from the inhibitory action of the primary organizer and supernumerary organizers are formed (blue/green: activator; $\beta$-catenin Wnt3; see Fig. 4); red: inhibitor; turquoise: competence, (i.e., the source density in the notation of Gierer and Meinhardt, 1972). (B) Observation: if $\beta$ catenin is ubiquitously activated, all regions become competent, no gradient is left and many heads appear at closer spacing (Gee et al., 2010; see also Fig. 7E). This observation supports the view that a Wnt3 peak needs a high $\beta$-catenin level but not a $\beta$-catenin maximum. (C) By a long-ranging feedback of the organizer onto the competence, cells distant to the organizer loose competence and therewith the chance to trigger a new organizer as long as the original organizer is present. Due to the graded and relatively stable competence, any fragment regenerates with the original polarity. The competence is part of the feedback system and is restored during regeneration. In this simulation it is assumed that the long-ranging inhibitory Wnt3 molecules (red) accomplish this feedback. A higher competence is realized by a higher $\beta$-catenin production, while for degradation and stabilization of $\beta$-catenin the standard Wnt signaling is assumed. The molecular basis of the competence, however, is not yet known. (D) $A$ small hydra can grow substantially without loosing its polarity. Small fragments regenerate with normal polarity. (B) by courtesy of Hans Bode, from Gee et al., 2010, Dev. Biol. (with permission). tain transplantation experiments. In particular, the very tip of the hypostome is most efficient in inducing a second axis (Browne, 1909; Broun and Bode, 2002) (see Bode, this volume). In terms of the model, after transplantation of hypostomal tissue into the body column, the few cells with high Wnt3 expression initiate via

a relatively broad maximum and another that generates a very sharp peak, is an effective strategy to achieve reliable tissue to find the best place for activation, including that peak formation takes place preferentially at a marginal position. In contrast, the local peak allows, for instance, the formation of the spatially very restricted oral opening of the gastric column. The strong coupling keeps the two patterns in register. If a system that leads to sharp local maxima would be employed in the first place, more than one maximum would form initially. Some of them would disappear due to the emerging competition, more than one could survive and the position of the surviving peak(s) could not be corrected or optimized.

\section{Why Wnt3-Brachyury peaks expand in the course of time}

The sharpening of the $\beta$-catenin peaks (Fig. $5 \mathrm{~A}-\mathrm{C}$ ) is a straightforward consequence of the lateral inhibition mechanism: a local elevation causes the inhibition of the surrounding cell, which leads to the confinement. In contrast, the initially very sharp Wnt3/Bra maxima that become broader in the course of time require an explanation. As mentioned, the second loop is assumed to be cell-local. If no diffusion and no limitation of the maximum activator concentration would be involved, the maximum would eventually consist of a single activated cell. With saturation in the self-enhancement, however, also the inhibitor production of a cell has an upper limit. Consequently, the lateral inhibition is less effective and an activated cell has to tolerate other activated cells in its vicinity. Without diffusion of a component of the self-enhancing reaction, there would be no "community"-effect; activation would occur in a scattered manner and not in coherent peaks. However, since the $\beta$-catenin is the precondition to activate the cell-local loop, the first cells that trigger are those exposed to the highest $\beta$-catenin level. Nearby cells, exposed to a somewhat lower $\beta$-catenin level will follow. In other words, the expression domain of the Wnt3 peak (and of Brachyury) starts with a few cells and enlarges. The final size will depend on the $\beta$-catenin -level and the extension of the non-activated tissue into which the inhibitor can escape, i.e., saturation leads to a size regulation 
of the peaks (Gierer and Meinhardt, 1972).

\section{Important for the maintenance of axial organization: suppression of supernumerary organizer formation during growth}

In the course of growth, a standard pattern forming system can maintain a graded distribution only over a range of about a factor two or three. During further growth, cells can escape from the inhibitory influence of the primary organizer, which could lead to the trigger supernumerary organizers (Fig. 6). The insertion of new maxima during growth is a frequent event in many developmental systems. Examples are the insertion of new leaves at a growing shoot, of new trichomes in growing leaves (reviewed in Balkunde et al., 2010) and of new heterocysts in Anabaena (Huang et al., 2004, Risser and Callahan, 2009). Thus, to maintain a polar body axis in a substantially growing animal, special mechanisms are required to suppress the formation of additional organizing regions. One possibility is the employment of maternally-supplied determinants. Since only a small region becomes competent, organizer formation at other positions is impossible. In the amphibian egg, for example, local determinants make sure that only one Spemann-organizer region can be formed although the egg is huge. This has a price. After removal of the competent region, regeneration is no longer possible, as demonstrated by the inability of ventral halves of amphibian embryos to regenerate dorsal structures.

\section{The role of a graded competence in the maintenance of a polar body pattern}

Both hydra and planarians maintain both the capability to regenerate and their polar body pattern in spite of substantial growth. Obviously both systems escape to some degree from the constraints mentioned above. Two mechanisms are involved. One consists in the formation a second and locally exclusive organizing region, the foot, at the antipodal position - the position that would be most vulnerable for the trigger of a supernumerary organizer. The other mechanism consists in a dynamically-regulated graded competence; cells distant to the organizer loose the ability to form a second one. Both mechanisms are crucial for hydra patterning and will be discussed below in more detail.

The polarity reversal as observed during regeneration of simpler systems (Fig. 2C) shows that the maintenance of polarity during regeneration in hydra and planarians is not trivial.

In many insect tissues the global polarity results from a polarity of the individual cells whose polarities are all aligned, generating in this way the so-called planar cell polarity, PCP (reviewed in Bayly and Axelrod, 2011). Experiments have shown, however, that this mechanism does not play a decisive role in the generation of the overall polarity in hydra. If aggregates are prepared from near-head and from near-foot tissue and these aggregates are combined, the near-head-derived cells will form the new head and most of the tentacles (Gierer et al., 1972). This indicates that the cell
A

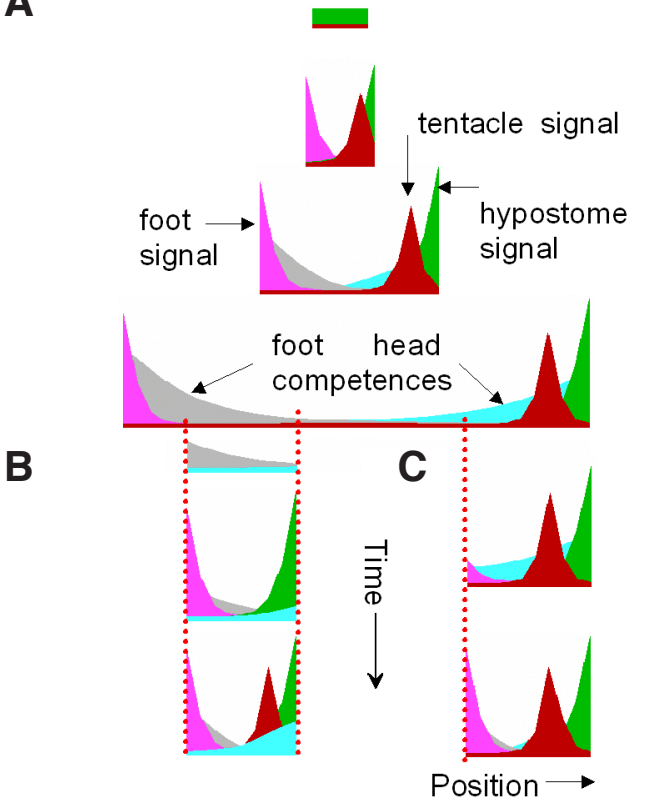

D
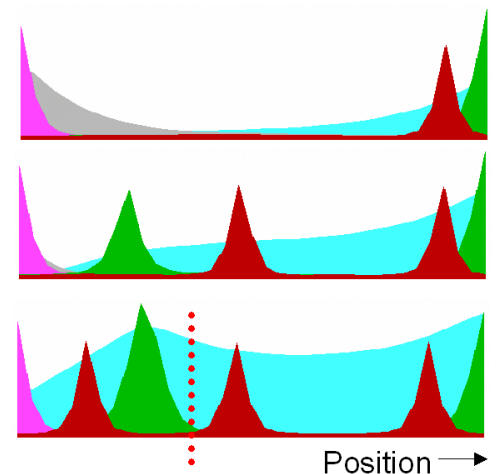

E

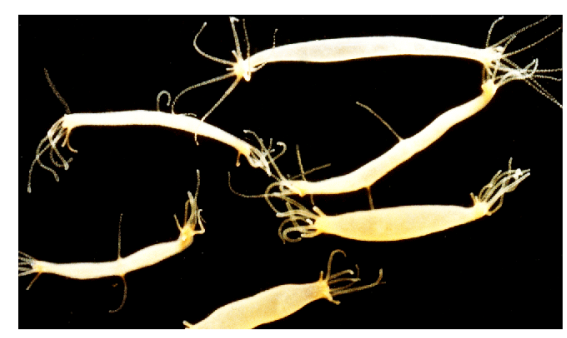

$\mathbf{F}$
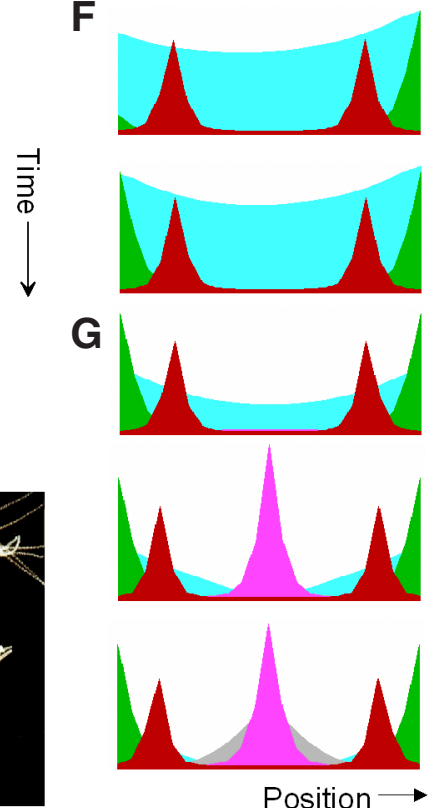

Fig. 7. Model for the head-foot patterning in hydra. (A) Primary head (green) and foot activation (pink) appear at opposite ends of the field due to a coupling via the head competence (light blue) and foot competence (gray). Both the head and the foot signal have a positive feedback on the corresponding competences. Head and foot competences mutually down-regulate each other; foot competence may correspond to the expression of NK-2 in hydra. Tentacle activation (red) appears close to the hypostome since it requires a high head competence but it is locally suppressed by head signal (see also Fig. 10). (B,C) Any fragment of sufficient size regenerates all missing structures. In the course of time also the competences are restored. In a small fragment that contains the head (C), foot regeneration is nevertheless possible since there is no direct inhibition of the head onto a foot. (D) After ubiquitous elevation of the head competence, ectopic heads and supernumerary tentacles are formed. (E) Such patterns are observed in animals treated with GSK-3 $\beta$ inhibitors, i.e., with drugs that block $\beta$-catenin degradation (Müller, 1989). (F) Foot removal of treated animals (at the dotted line in (D) can lead to the regeneration of a head instead due to the low foot-forming and high head-forming competence. (G) After removal of the drug, in such symmetrical animals a new food can appear in the center. In this simulation only a single loop is assumed for head activation (Fig. E kindly supplied by Werner Müller, see Müller, 1989). 
composition of the tissue, not the original polarity and alignment of the cells is decisive.

As determined by transplantation experiments in hydra, the ability to form the oral organizer is graded over almost the entire body length (reviewed in this issue by Shimizu, 2012). The long-range inhibition involved in pattern formation is likely to establish a relatively more stable property graded across the tissue. Presumably, this is manifested by a graded concentration of enzymes, receptors etc. that are involved in the production of activators and inhibitors and, in this sense, act as their sources (our original term). They endow the tissue with "competence" to generate signals to form certain structures. In the hydra literature this property is frequently called head activation gradient. This term, however, is ambivalent; source is not activation; the head activation gradient and the head activation would have a completely different extension and function. Therefore, I will use in the following the term "competence".

The idea is that from the organizer a long-ranging signal spreads that causes an increase of the competence, i.e., an increase of the ability of the cells to perform the pattern-forming reaction (Meinhardt, 1993). With increasing distance to an existing maximum, not only the inhibitor concentration butalso the competence decreases (Fig. $6)$. The cells become less and less able to establish a new centre, especially as long as the primary organizer is present. Thus, the graded competence has a very important function; it enhances dramatically the dominance of the primary organizing region. An embryo can grow to much larger sizes and maintain, nevertheless, its polarity. Regeneration remains possible, in contrast to systems where localized competence is achieved by maternal determinants.

In such a scheme the organizer has two apparently contradictory impacts on the surrounding tissue. On the one hand, via the inhibitor, it suppresses the formation other organizing regions. On the other hand, it enhances the competence of the tissue to enable, e.g., the regeneration of an organizer. Why both features do not cancel each other? Both effects are expected to have about the same range, but completely different time constants. The inhibitor (or the system that mediates the long-range inhibition) must have a high turnover to allow rapid regeneration after organizer removal. In contrast, the competence is a relatively stable tissue property that remains almost unchanged during the time required to form the new head signal during regeneration. This expected long time constant of the competence agrees with classical transplantation experiments according to which polarity reversal takes several days (Wilby and Webster, 1970a,b; Shimizu, 2012).

In a fragment, the graded competence is decisive for the orientation of the regenerating pattern, whereas the pattern itself is newly generated in a self-regulating manner (Figs. 6, 7). The new organizer will always appear at a marginal position. The model describes correctly that the same tissue can regenerate a head, a foot or remains a part of the body column, depending on its relative position in the fragment. A further effect of the graded competence is that regeneration of an organizer occurs much faster since the time required until one side becomes dominating is much shorter. Also the risk of forming two organizers upon regeneration is reduced.

The predicted different time constants have been impressively demonstrated in a recent experiment. After application of Alsterpaullone, a drug that stabilizes $\beta$-catenin (Bain et al., 2003), all cells obtain a high competence (Gee et al., 2010). After removal of Alsterpaullone, the tissue maintains a high competence for several days as examined by transplantation experiments while
A

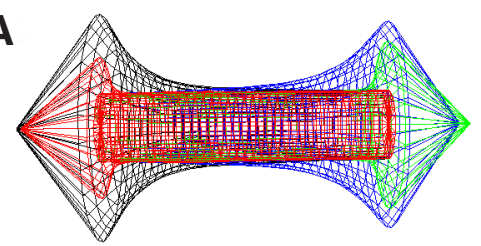

B
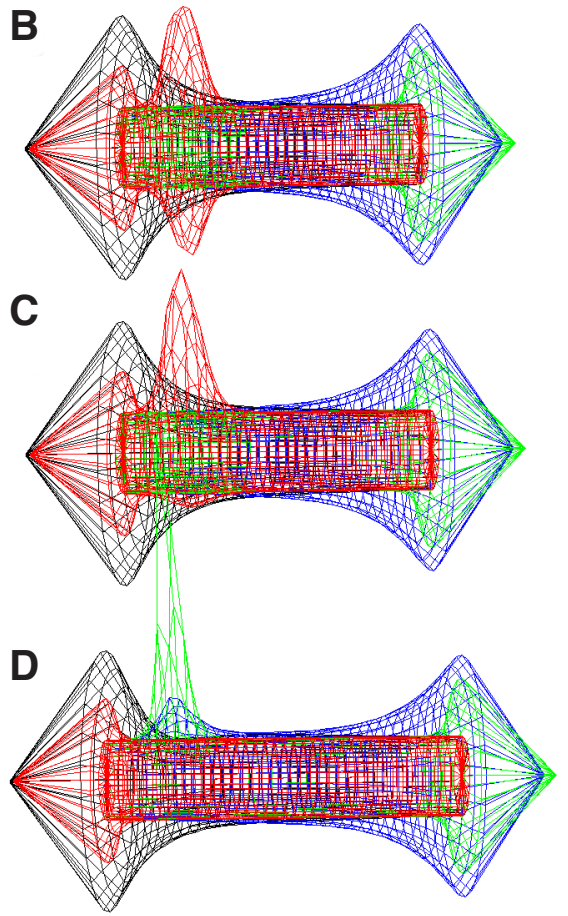

$\mathbf{E}$

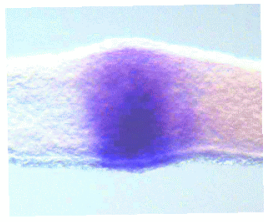

$\mathbf{F}$

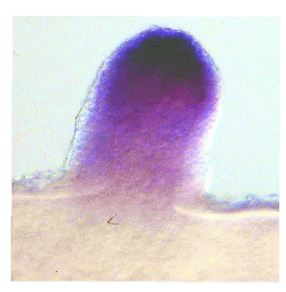

G

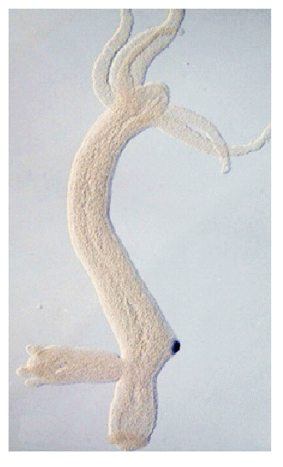

Fig. 8. Model for bud initiation. (A-D) The signal for a new bud is assumed to be inhibited by signals from the head (right) and from the foot. Thus, the bud signal can appear only after a certain size is obtained. The signal appears first as a ring that sharpens subsequently to a lateral spot. To initiate foot preparation close to an existing foot and close to the incipient head of the bud it is assumed that first a transient pre-bud signal is generated (e.g., Wnt2; red; see also Fig. 9) that becomes subsequently replaced by the final head signal of the bud (e.g. Wnt3, green; other colors as in Fig. 7). (E,F) Observations: Tcf (and $\beta$-catenin) has first a ring-shaped expression pattern before it becomes localized in the bud. (G) Wnt2 is expressed only at early bud stages. (Figs. (E, F) from Hobmayer et al., 2000); (G) from Lengfeld et al., 2009; figures kindly provided by Thomas Holstein, with permission of "Nature" and Dev. Biol.).

$\beta$-catenin returns much faster to normal. Thus, the competence must be a long-lasting tissue property downstream of $\beta$-catenin. From their distribution, the long-ranging Wnt3 molecules would be an appropriate mediator. However, the molecular realization of the competence is not yet known.

\section{Keeping maximum distance: head-foot patterning}

Since the graded head competence accounts for the formation of the head signal at the one terminal end, it was suggestive that a similar system localizes foot formation at the opposite position. In an earlier model, it was assumed that the competence for the foot was just the inverse of the competence for head formation: what is good for the head is bad for the foot and other way round. In addition, the foot system was assumed to reduce the head competence even further, contributing in this way to the overall 
polarity of the animal. This model was able to account for the correct terminal regeneration of the head and the foot in any fragment (Meinhardt, 1993).

Meanwhile several gene expression data became available that allow to make the model more specific. Competence for foot formation seems to be given not just by a low competence for head formation. The expression of the gene $N k-2$ has a graded distribution, precedes foot formation in all situations and turned out to be a measure for foot competence (Grens et al., 1996). The basal disk, the most aboral structure in hydra, is formed in a region much smaller than the region of the Nk-2-expression. Thus, the head and the foot systems show many parallels. Localized signals form at the terminal ends. The preconditions to form these signals are more graded competences that are in a delicate equilibrium. An elevation of one of these competences leads to a reciprocal shrinkage of the other (Grens et al., 1996; Reinhardt et al., 2004; Philipp et al., 2009).

These manipulations opened an inroad to investigate the relation between the competences on the one hand and the signal proper on the other. After increase of the head competence, supernumerary head structures are formed while basal structures can disappear (Müller, 1989; Fig. 7). Other way round, after Lithium treatment known to reduce the head competence - several basal disks can show up (Hassel and Berking, 1990). In full agreement with the model that we proposed, the competence is decisive whether and, to some extend, how close particular signals can emerge. In contrast, if the signal is generated, its extension is essentially independent of the competence. The simulation in Fig. 7 shows that these features are reproduced by the model. As a first approximation, it is assumed that both the head and foot system are based on very similar types of interactions. The model accounts for the maintenance of the polar pattern during substantial growth and for the regeneration of small fragments with preserved polarity.
During regeneration a balanced ratio of the competences becomes restored in the course of time. Supernumerary structures appear after manipulation of the competence (Fig. 7D). The model reconciles the coexistence of a head and a foot in small animals and the localization of both signals at the largest-possible distance during growth and regeneration. Thus, the model describes foot regeneration close to an existing head since one system determines only the preferred position of the other without a direct long-ranging inhibition (Fig. 7C). Not yet incorporated is that an existing head has a helping influence on foot regeneration (Müller 1995). Also it is unclear why especially in more aboral fragments apoptosis is required to release sufficient Wnt3 to initiate head regeneration (Chera et al., 2009; Galliot, this volume).

\section{Budding}

From the modeling point of view, the generation of a new head signal at a particular position of the body column is straightforward. The interactions can be tailored such that a new head signal can emerge whenever a certain minimum distance from the head and from the foot is exceeded. The model was predicting that the signal for the first bud appears as a ring that surrounds the body column (Meinhardt and Gierer, 1974). Due to the lateral inhibition within this ring, a single peak eventually emerges (Fig. 8). This ring is especially noticeable in the initiation of the first bud since in subsequent buds the asymmetry generated by the preceding bud leads to a more rapid confinement of the peak to the opposite position.

Achallenging problem in modeling bud formation is the initiation of the bud-foot, a prerequisite for the separation of the bud from the parental animal. This foot has to be initiated relatively close to the signal that leads to head formation of the emerging bud. Thus, if the signal that initiates the normal head and the head of the bud would be identical at all stages, an inductive signal from
A

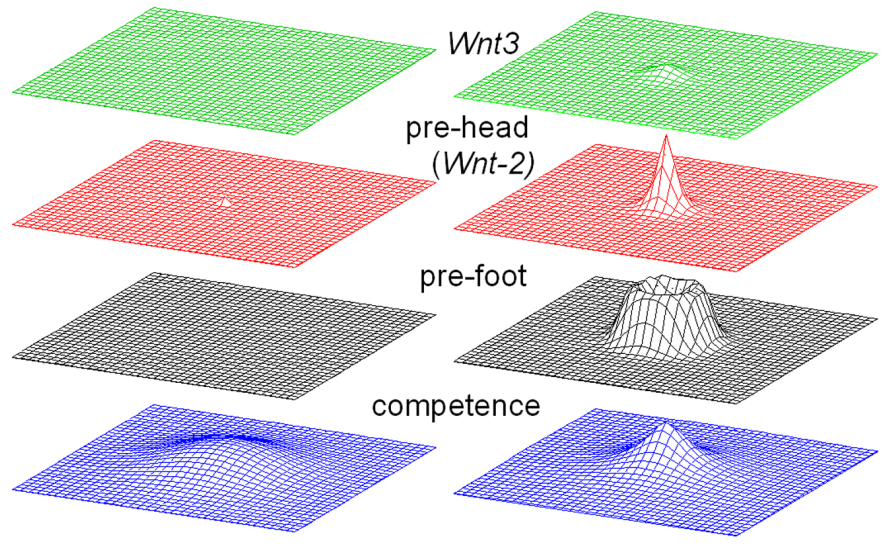

B Wnt3 re-head (Wnt-2)

pre-foot
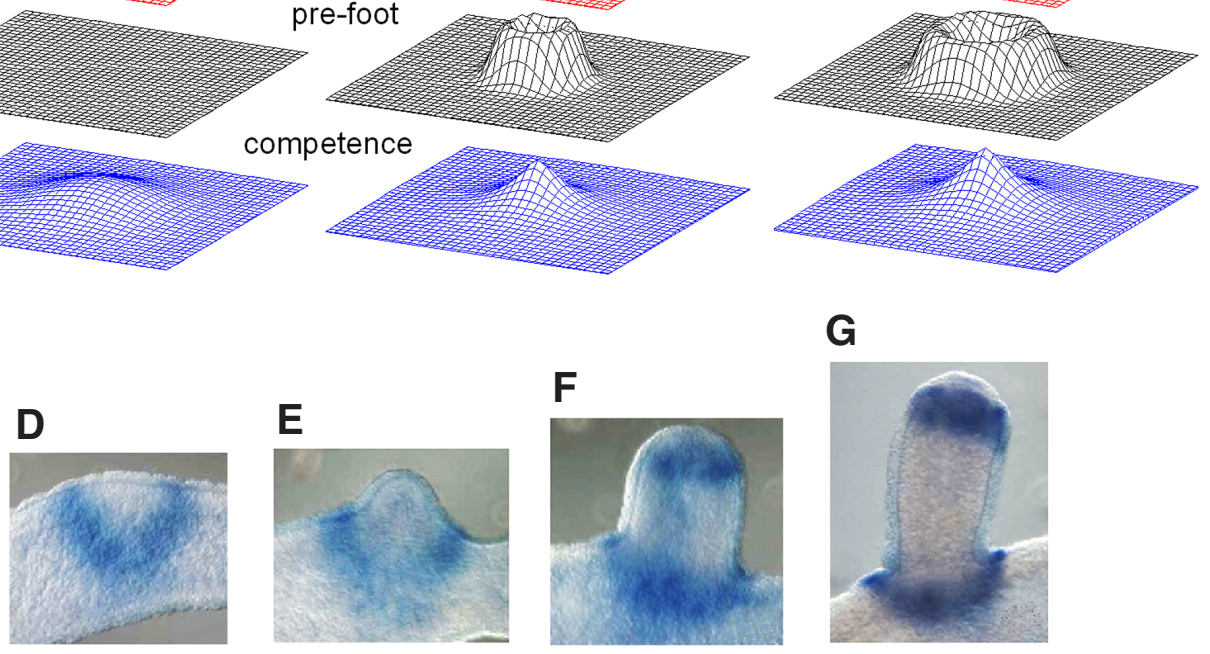

$\mathbf{E}$

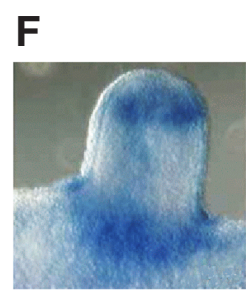

G

C
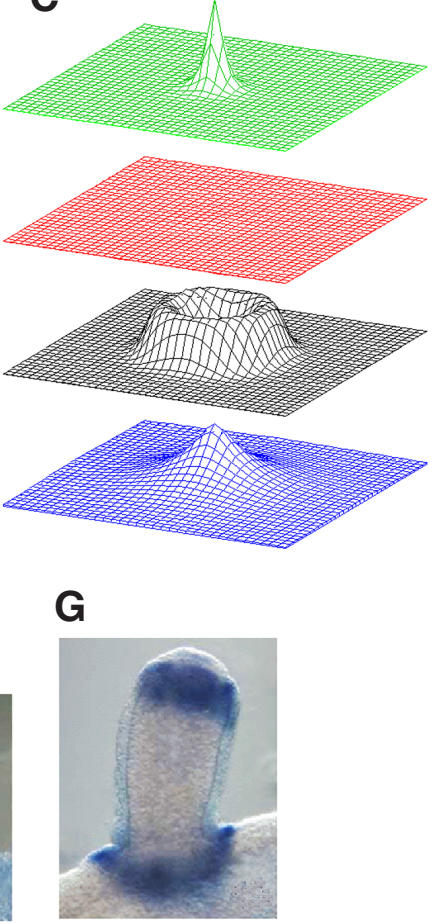

Fig. 9. Model for preparing foot formation in a newly formed bud. (A,B) Proposed is that first a transient "prehead" signal (red; possibly Wnt2; see Fig. 8) is generated that, in turn, activates on longer range but excludes locally the signal required for foot preparation (black). The pre-foot signal forms a ring that surround the bud signal. Due to a saturation of the self-enhancement, the signal does not disintegrate into spots (as occurring during tentacle formation, see Fig. 10). Subsequently, the pre-bud signal is replaced by the proper signal for head formation of the bud $\mathrm{Nnt} 3$, green). This is accomplished by the increasing competence (blue) generated by the new bud signal. (C) Since the pre-foot signal is an independent pattern-forming system, it remains activated after the pre-head signal is gone. (D-F) The ring-shaped expression of disheveled at the base of the bud is assumed to be generated in this way (Photographs kindly supplied by Isabelle Philipp and Bert Hobmayer, see supplementary material of Philipp et al., 2009). 
the bud-head to form an adjacent bud-foot would also induce a new foot close to the normal head, which is obviously not the case. This problem disappears if the initial signal for bud formation is not identical with the initial signal, e.g., in head regeneration. $A$ candidate is Wnt2 that is only transiently expressed during early stages of bud formation (Fig. 8). It is assumed that the purpose of the transient signal is to induce the preparatory steps for bud formation including the bud-foot. Shortly thereafter, the bud-specific signal is replaced by the normal head signal, e.g., Wnt3. On the basis of such a model it is expected that the foot-preparing signals can be activated only during a short time window at early bud stages. Indeed, the Delta-Notch system is required for bud-foot formation (Münder et al., 2010). Blocking Delta-Notch during a crucial time interval abolishes permanently foot formation and the detachment of this particular bud. The result is the formation of a second axis. Subsequently formed buds separate normally also in the non-detached branch.

During early bud stages, foot-preparing signals such as Dishevelled surround the bud initiation side in a circular manner (Fig. 9). These signals are involved to accomplish the necessary shape change of the cells as they pass from the body column into the bud (Philipp et al., 2009). Thus, although the foot-ring is induced by a signal from the incipient bud tip, the foot ring must remain stationary at the border between the body column and the bud while the tip of the bud obtains an increasing distance from the body column. The situation is, therefore, very different from the hypostome-tentacle relation where the center-surround - pattern is maintained. This is presumably a second reason why the bud-initiating signal has to disappear. Otherwise, the ring would move with tip of the bud due to its inducing influence, as it is the case for the tentacle signal. In Fig. 9 a model is shown where (i) a pre-head signal of the bud induces the pre-foot ring, (ii) the prehead - signal induces the final head signal and, (iii), the final head signal down-regulates the pre-head signal, making the induced pre-foot ring free to enlarge and become independent of the tip of the bud. It is worth to note that the pre-foot ring should not decay into patches as it is the case during tentacle formation (see below). As shown in the simulation, this indicates that a saturation of the self-enhancement plays a decisive role. Such a saturation has also the effect that the cells can move through this zone - they become activated as they enter and de-activated as they leave the zone a behavior that is obviously required for cells that move from the body column into the bud.

\section{Tentacle formation: how to form different structures close to each other}

Tentacles appear close to each other in a sub-hypostomal ring. The periodic nature of the tentacle pattern indicates that they are formed by a separate pattern forming system. The close spacing around the circumference on the one hand and the absence of additional tentacles further down the body column on the other can be explained by assuming that the graded competence for the head-forming system represents also the competence for tentacle formation, while, locally, the hypostome system inhibits the tentacle system. Thus, tentacle formation is restricted to the sub-hypostomal region since there both conditions are satisfied: the hypostomecontrolled competence is high and the inhibitory influence of the hypostome is sufficiently low (Meinhardt, 1993) (Fig. 10).
After head removal a tentacle-specific signal appears first as a patch at the oral end of the fragment. Only later the signal shifts from the tip towards the final position, forming first a nearhypostomal ring that disintegrates into individual patches at which the tentacles will eventually emerge (Bode et al., 1988; Smith et
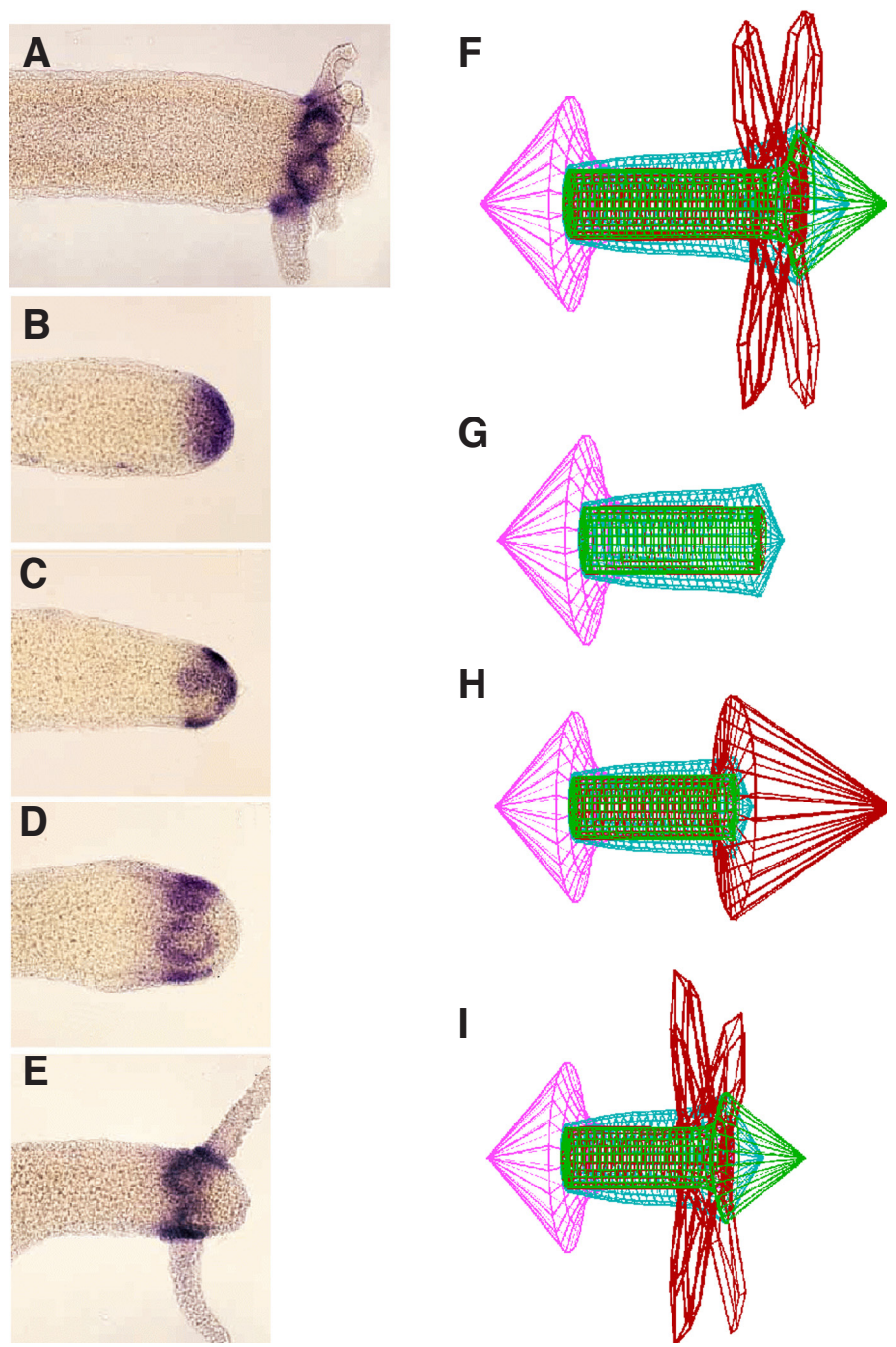

G

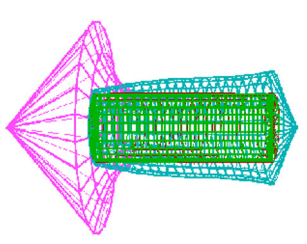

H
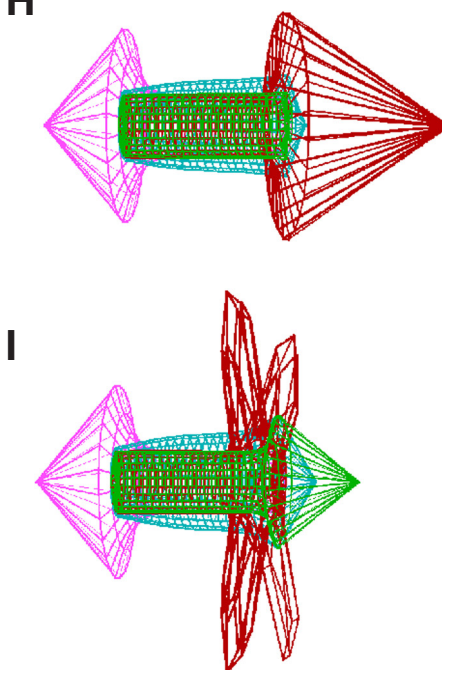

Fig. 10. Relation of hypostome and tentacle formation. (A) Expression of HyAlx in a normal hydra at the base of the tentacles (Smith et al., 2000). (B-E) During regeneration, HyAlx expression appears first at the most oral position and moves subsequently to the final position at which the tentacles eventually form. (F-I) Model: The signals for tentacle formation (brown) are assumed to require a high competence (blue) but the absence of the head signal (green); thus, tentacles form at a sub-hypostomal position. After head removal, the competence can be high enough to trigger the tentacle signal directly. The tentacle signal appears first at the most oral position, and becomes later shifted to the final position under the inhibitory influence of the regenerating head system. During this shift the tentacle signal disintegrates into discrete peaks. The model predicted that the sequence of events is the reverse during tentacle formation in a region of low competence, e.g., during budding (Meinhardt, 1993). There the head signal is formed first and the tentacle signal is formed directly at the final position (see Fig. 7B). This prediction turned out to be correct (Technau and Holstein, 1995; Smith et al., 2000). Simulation on a cylinder; concentrations are plotted as the distance from the cylinder. (A-E) Kindly provided by Hans Bode, with the permission of Dev. Biol. 
al., 2000; Reinhardt, et al., 2004) (Fig. 10). In terms of the model, in a near-head region the competence can be high enough that tentacle formation is triggered directly at the position with the highest competence. With the regeneration of the hypostome system, the tentacle signal is sifted to a sub-hypostomal position (Fig. 10).

The shift of the tentacle signal is non-trivial. Usually, peaks generated by an activator-inhibitor system are hardily movable since the surrounding of a maximum is strongly inhibited. However, shifting becomes possible if the self-enhancing reaction saturates at high levels. Then, the activator concentration has an upper bound. Therefore, also the maximum inhibitor production per cell is reduced. More cells become activated although at a lower level. The peaks obtain a more plateau-like profile. By an inhibitory influence from the hypostomal region, the activation may decrease on one side, which is compensated by an increase at the other side of the plateau. Fig. 10 illustrates this theoretically expected shift and the observed expression pattern of the Aristaless gene.

According to the model, the saturation of the self-enhancement as deduced from the shift of the tentacle signal also contributes to the possible dense spacing of the tentacles. Since the maximum inhibitor production in a cell is limited, maxima can emerge much closer together without mutual downregulation. Nevertheless, together sufficient tentacle-inhibitor is produced in these densely
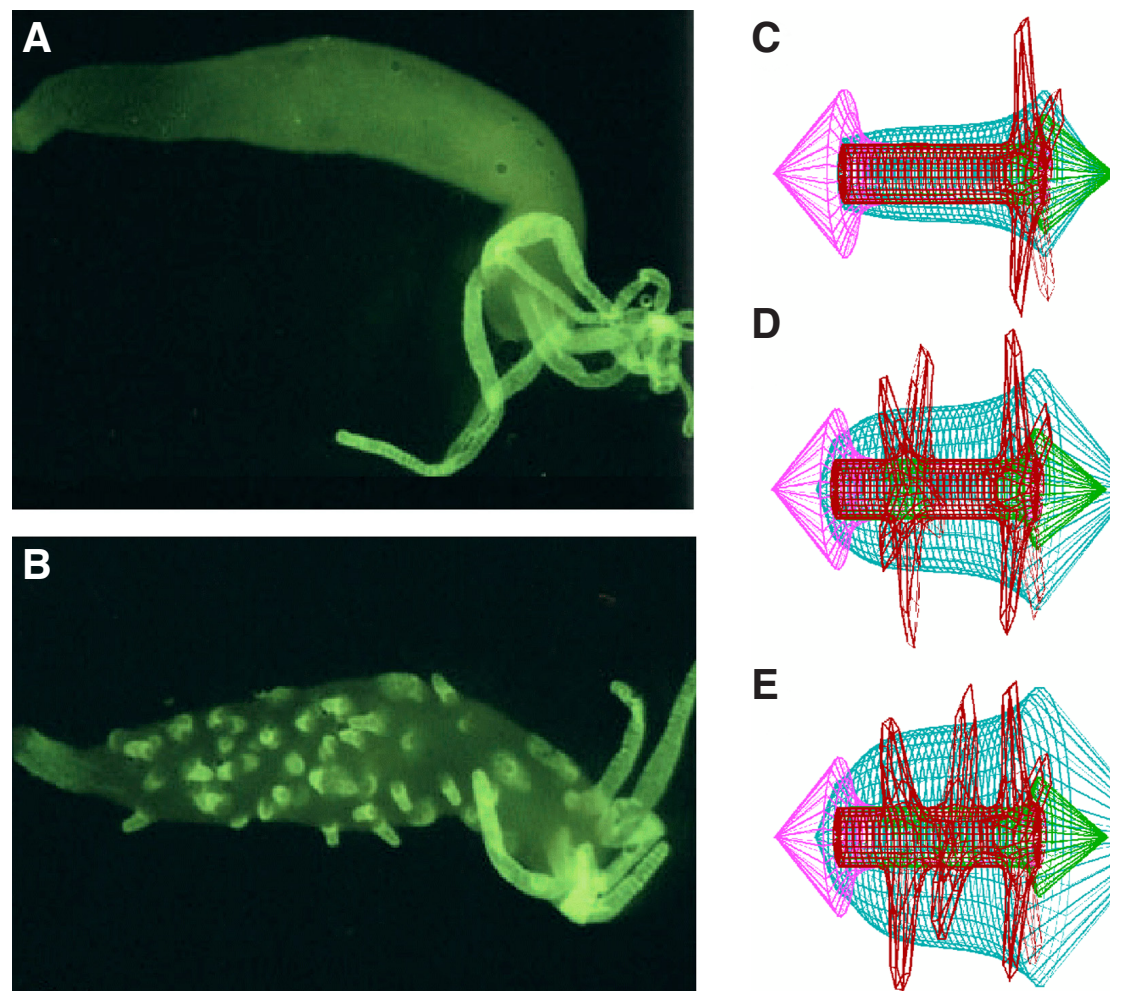

E

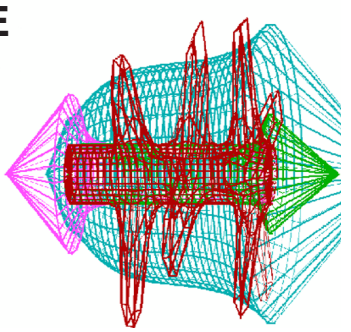

Fig. 11. Multiple tentacle formation after Alsterpaullone treatment.(A) Staining with a tentacle-specific antibody. (B) After treatment with Alsterpaullone (that stabilizes $\beta$-catenin) tentacle formation occurs all over the body column (Broun et al., 2005). (C-E) Model: tentacle formation is normally restricted to a region where the head-forming competence (blue) is high but the local inhibition of from the hypostome is low (see Fig. 10). Treatment with Alsterpaullone increases the competence (blue) in the body column. The position next to the hypostome is no longer privileged; tentacles appear all over with a similar spacing that is normally only observed in the tentacle ring. As observed, the first supernumerary tentacles appear at some distance from the normal tentacles due to their inhibitory influence. Photographs kindly provided by Hans Bode; "Development," with permission). packed tentacles to suppress additional tentacles along the body column. If the saturation would be even stronger, the tentacle cour formation, the graded competence for tentacle formation leads to substantial increase of the "apical dominance" of tentacle formato have no feedback on the competence.

As mentioned, recently it became possible to manipulate the competence by treatment with the $\beta$-catenin - stabilizing drug (Broun et al., 2005). As expected from the model, with the overall increase of the competence, the restriction of the (heneration of tentacles all over the body column and the reproafter other treatments that elevates the head competence (Fig. $7 \mathrm{E} ;$ Müller, 1989). The dense spacing in the absence of a graded

reviles the natural short range of tentacle inhibition. Remarkably, this overall tentacle formation does not occur in germlinetransformed animals with elevated $\beta$-catenin levels (Fig. 6B; Gee et al., 2010). Presumably there is still a residual gradient in the competence that is sufficient for tentacle localization.

Also for tentacle formation the Wnt pathway is crucial; Wnt5 is expressed in the tentacle tip, Wnt8 in a ring at the base (Philipp et al., 2009). Since the tip separates from the base during tentacle outgrowth, both activations have to be complete pattering systems. Since both activations are under Wnt3 control, tentacle formation is another example of the Wnt code mentioned above. According to the model this became possible by the activator-inhibitor double function of each family member.

With a Wnt-signal at the tentacle tip and BMP5$8 b$ at their base (Philipp et al., 2009; Reinhardt et al., 2004), the expression patterns along a tentacle and along the body axis shows remarkable parallels. Tentacles were certainly a later addition during evolution. At the time the basic axial structure of the hydra ancestor evolved there was no prey for capturing with tentacles. This suggests that tentacle formation evolved as the prey became available by a cooption of a budding-like process in which the detachment of the buds became suppressed. In this view, tentacles are "domesticated" buds.

\section{Models for the bilaterian body plan inspired by the models for hydra patterning}

Hydra and its relatives are at the base of the metazoan evolutionary tree. The axial organization of hydra is therefore expected to provide hints for ancestral axial organization including the preconditions for the evolution of the bilateral body plan. Many genes expressed in hydra are found in the brain of higher organisms (Galliot, 2000; Galliot and Miller, 2000), suggesting that the evolutionary invention of the head is very old. The expressions of Wnt and Brachyury in the hypostome suggested that the 


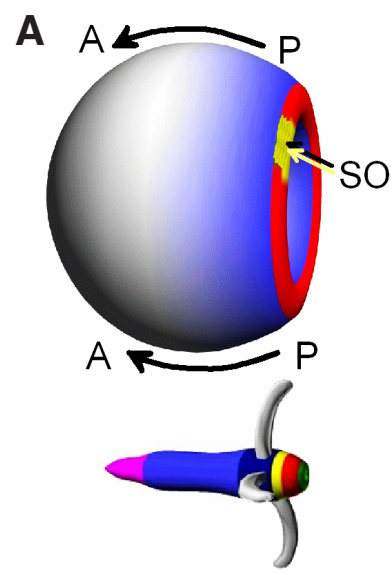

B

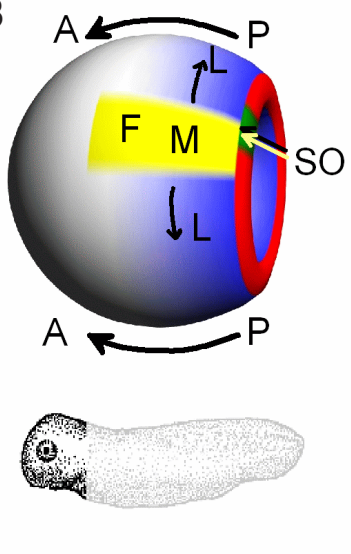

C
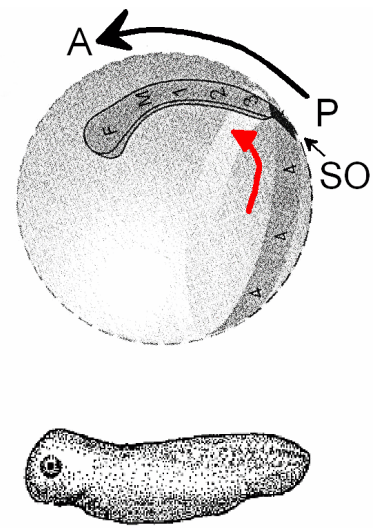

Fig. 12. The relation of axis formation in hydra and vertebrates. (A) AP patterning of the early gastrula is assumed to be accomplished by a system that was already involved in the body patterning of ancestral organisms. The marginal zone (red; Brachyury, Wnt) is assumed to be equivalent to the hydra organizer. These blastoporal rings, small in hydra and huge in amphibians, are the source region of Wnt signaling that control anteroposterior determination of the future brain region in a gradient-based manner (Kiecker and Niehrs, 2001). The Chordin-based Spemann organizer (SO, yellow) is located on this marginal zone, i.e., on this ancestral hydra-type organizer. (B) With the movement of the mesodermal cells of the marginal zone between the inner endoderm and outer ectoderm, the organizer-derived cells form the prechordal plate (yellow) in the future head region. It acts as the midline organizer for the mediolateral (L-M-L) patterning and induces neuronal development in the overlying ectoderm. The distance from this midline determines the mediolateral specification in the brain, for instance, the distance and symmetrical arrangement of the eyes. Both signaling sources, the ring of the marginal zone and the prechordal plate, have a stripe-like extension with orthogonal orientation; together they provide a near-Cartesian positional information system for patterning the fore- (F) and midbrain (M). (C) The trunk, assumed to be an evolutionary later addition, is formed by a time-based posteriorization $(1,2,3,4 \ldots)$ accomplished by a sequential activation of HOX-genes in cells near the marginal zone as convincingly demonstrated (Wacker et al., 2004; see also Duboule, 2007). In a ring-to-rod conversion, the cells near the marginal zone move towards the Spemann-organizer and the incipient midline, forming in this way the AP pattern of the trunk (after Meinhardt, 2006; 2008).

so-called head corresponds to the most posterior structure, the blastopore. In contrast, the gene characteristic for the hydra foot, $N k x-2$, is anteriorly expressed in many higher organisms (Tonissen et al., 1994). Nkx2.5 is a gene characteristic for vertebrate heart formation. Based on this gene expression, on the response to drugs and on the pulsating pumping activity, the hydra foot and the vertebrate heart were proposed to have a common ancestry (Shimizu and Fujisawa, 2003). Otx, a gene characteristic for the fore- and midbrain in higher organisms, is expressed in hydra all over in the body column except of the extreme ends. Together, these expression patterns suggested that ancestral bag-like organisms with a single opening evolved in the most anterior (and most important) part of higher organisms, the brain and the heart (Meinhardt, 2002). Thus, unexpectedly, it is the foot-to-head extension in hydra that corresponds to the anterior-posterior axis in higher organism.

The Otx expression provides further information for the relation of ancestral and actual axial patterning. The hydra organizer is located posterior to Otx border (blue - yellow border in Fig. 12; the Otx - Gsc/Bracchyury border). This region is also in vertebrates an organizing region, the midbrain-hindbrain border (Wurst and BallyCuif, 2001). The absence of the trunk-typical HOX-gene clusters in hydra (Gauchat et al., 2000; Kamm et al., 2006) indicates that the trunk was an evolutionary later invention. With the insertion of the trunk, the hydra-type organizer became displaced to more posterior positions, suggesting that the midbrain-hindbrain organizer was a secondary organizer left in place as the primary organizer became displaced. Most remarkable, during ontogenetic development of most organisms, the initiation of brain development usually precedes that of the trunk, recapitulating in this way the sequence of evolutionary innovations.

Usually, organizing regions are envisioned as a patch of cells with special signalling properties. However, to generate the body plan for a bilateral-symmetric and long extended animal it was required to form a line of reference for the dorsoventral (or mediolateral) patterning. The formation single straight stripe-shaped organizer is an intricate patterning process that requires several coupled pattern-forming reactions. Different solutions have been found for this important step during evolution (Meinhardt, 2004, 2006). In vertebrates, starting with the Spemann organizer (which is located on the blastopore, the ancestral-hydra-type organizer), the midline is generated by an elongation towards anterior (prechordal plate) and towards posterior by the moving node (Fig. 12). The moving node gives rise to the most dorsal structures, floor plate and notochord during trunk formation. Thus, for the DV patterning, not the distance to the Spemann organizer but the distance to the midline, which is initiated by the organizer, is measured. In contrast, in insects, a dorsal organizing region inhibits midline formation. Thus, the midline and the central nervous system appear at a most ventral position. While in vertebrates the midline is elongated along the $\mathrm{AP}$ axis, in insects the midline has from the beginning the full AP extension but becomes compressed and sharpened along the DV axis to be eventually confined to a most ventral position (Meinhardt, 2004). This model-prediction (Meinhardt, 1989) found full support by recent observations (Chen et al., 2000, da Fonseca et al., 2009). Well-known is DV-VD polarity reversal between vertebrates and insects (Arendt and Nübler-Jung, 1994). The models for midline formation provide a new explanation. In vertebrates, the dorsal organizer initiates the midline dorsally and the CNS will be dorsal. In contrast, in insects the dorsal organizer repels the midline to a ventral position. The CNS is, therefore, ventral.

\section{Conclusion}

As in other branches of science, theories are an indispensable tool to understand complex systems. Some decades ago the generation of a reliable patterned organism from an almost structureless initial situation was almost a mystery. Our theory has shown that relative simple mechanisms can account for essential steps of pattern formation during development as long as our condition 
of local self-enhancement and long range inhibition is satisfied. In a toolbox-like manner, several such reactions can be linked to each to assure a reliable spatial relation of the emerging structures. The inherent self-regulatory features of these mechanisms allow in many cases a faithful restoration of the normal pattern, even after heavy perturbations or after separation of body parts during asexual reproduction. Since these reactions require communication between cells by diffusion or related processes, it is to be expected that these regeneration processes are restricted to small systems such as hydra and planarians. It is to be expected that in larger systems the capability to perform primary pattern-forming processes is switched off to avoid aberrant patterning.

Meanwhile several of the predicted components have been directly demonstrated on the molecular level. Nevertheless, the particular role of the components of the Wnt pathway in pattern formation was unclear. The hypothesis that secreted Wntmolecules have a double function - acting as activators and, after processing, as inhibitors - bridges a major gap in the understanding of the Wnt-pathway. Refined modeling together with new observations will certainly provide further insights into this most fascinating field.

\section{Note regarding Supplementary Material}

Details of the simulations, animated simulations, parameters, partial program codes and links to appropriate compilers are available in the Supplementary Material corresponding to this paper at: http://dx.doi. org/10.1387/ijdb.113483hm

\section{Acknowledgment}

I wish to express my sincere thanks to Prof. Alfred Gierer. Much of the basic work described in this paper emerged from a fruitful collaboration and exchange of ideas over many years.

\section{References}

ARENDT, D. and NÜBLER-JUNG, K. (1994). Inversion of dorsoventral axis. Nature 371: 26-26.

AUGUSTIN, R., FRANKE, A., KHALTURIN, K., KIKO, R., SIEBERT, S., HEMMRICH, G. and BOSCH, T.C.G. (2006). Dickkopf related genes are components of the positional value gradient in hydra. Dev Biol 296: 62-70.

BAFICO, A., LIU, G., YANIV, A., GAZIT, A. and AARONSON, S.A. (2001). Novel mechanism of Wnt signalling inhibition mediated by Dickkopf-1 interaction with LRP6/Arrow. Nat Cell Biol 3: 683-686.

BAIN, J., MCLAUCHLAN, H., ELLIOT, M. and COHEN, P. (2003). The specificities of protein kinase inhibitors: an update. Biochem. J. 371: 199-204.

BALKUNDE, R., PESCH, M. and HÜLSKAMP, M. (2010). Trichome patterning in Arabidopsis Thaliana: from genetic to molecular models. Plant Devel. 91: 299-321.

BARTSCHERER, K. and BOUTROS, M. (2008). Regulation of Wnt protein secretion and its role in gradient formation. EMBO Reports 9: 977-982.

BAYLY, R. and AXELROD, J.D. (2011). Pointing in the right direction: new developments in the field of planar cell polarity. Nature Rev. Genet. 12, 385-391.

BISGROVE, B.W., ESSNER, J.J. and YOST, H.J. (1999). Regulation of midline development by antagonism of Lefty and Nodal. Development 126: 3253-3262.

BODE, H.R. (2003). Head regeneration in hydra. Dev Dyn 226: 225-236.

BODE, H.R. (2012). The head organizer in Hydra. Int J Dev Biol 56: 473-478.

BODE, P.M., AWAD, T.A., KOIZUMI, O., NAKASHIMA, Y., GRIMMELIKHUIJZEN, C.J.P. and BODE, H.R. (1988). Development of the two-part pattern during regeneration of the head in hydra. Development 102: 223-235.

BOSCH, T.C.G. (2007). Why polyps regenerate and we don't: towards a cellular and molecular framework for hydra regeneration. Dev Biol 303: 421-433.

BROUN, M. and BODE, H.R. (2002). Characterization of the head organizer in hydra. Development 129: 875-884.

BROUN, M., GEE, L., REINHARDT, B. and BODE, H.R. (2005). Formation of the head organizer in hydra involves the canonical Wnt pathway. Development 132 2907-2916.

BROWNE, E.N. (1909). The production of new hydrants in Hydra by insertion of small grafts. J.Exp. Zool. 7: 1-23.

CHEN, G., HANDEL, K. and ROTH, S. (2000). The maternal nf-kappa b/dorsal gradient of Tribolium castaneum: dynamics of early dorsoventral patterning in a short-germ beetle. Development 127: 5145-5156.

CHEN, Y. and SCHIER, A.F. (2002). Lefty proteins are long-range inhibitors of squintmediated Nodal signaling. Curr Biol 12: 2124-2128.

CHERA, S., GHILA, L., DOBRETZ, K., WENGER, Y., BAUER, C., BUZGARIU, W., MARTINOU, J.C. and GALLIOT, B. (2009). Apoptotic cells provide an unexpected source of wnt3 signaling to drive hydra head regeneration. Dev Cell 17: 279-289.

DA FONSECA, R.N., LYNCH, J.A. and ROTH, S. (2009). Evolution of axis formation: mRNA localization, regulatory circuits and posterior specification in non-model arthropods. Curr. Opin. Genet. Dev. 19: 404-411.

DEROBERTIS, E.M. (2009). Spemann's organizer and the self-regulation of embryonic fields. Mech Dev 126: 925-941.

DUBOULE, D. (2007). The rise and fall of HOX gene clusters. Development 134: 2549-2560.

DUBOC, V., ROTTINGER, E., BESNARDEAU, L. and LEPAGE, T. (2004). Nodal and $b m p 2 / 4$ signaling organizes the oral-aboral axis of the sea urchin embryo. Dev. Cell 6: 397-410.

DUFFY, D.J., PLICKERT, G., KUENZEL, T., TILMANN, W. and FRANK, U. (2010). Wnt signaling promotes oral but suppresses aboral structures in hydractinia metamorphosis and regeneration. Development 137: 3057-3066.

GAUCHAT, D., MAZET, F., BERNEY, C,, SCHUMMER, M., KREGER, S., PAWLOWSKI, J., and GALLIOT, B. (2000). Evolution of antp-class genes and differential expression of hydra hox/parahox genes in anterior patterning. Proc. Natl. Acad. Sci. USA $97,4493-4498$

GALLIOT, B. (2000). Conserved and divergent genes in apex and axis development of cnidarians. Current Opinion in Genetics \& Development 10: 629-637.

GALLIOT, B. and MILLER, D. (2000). Origin of anterior patterning - how old is our head? Trends Genet. 16: 1-5.

GALLIOT, B. and GHILA, L. (2010). Cell plasticity in homeostasis and regeneration. Mol. Reprod. Dev. 77: 837-855.

GEE, L., HARTIG, J., LAW, L., WITTLIEB, J., KHALTURIN, K., BOSCH, T.C.G. and BODE, H.R. (2010). Beta-catenin plays a central role in setting up the head organizer in hydra. Dev. Biol. 340: 116-124.

GIERER, A. (1977). Biological features and physical concepts of pattern formation exemplified by hydra. Curr. Top. Dev. Biol. 11: 17-59.

GIERER, A. (2012). The Hydra model - a model for what? Int J Dev Biol 56: 437-445.

GIERER, A., BERKING, S., BODE, H., DAVID, C.N., FLICK, K., HANSMANN, G., SCHALLER, H. and TRENKNER, E. (1972). Regeneration of hydra from reaggregated cells. Nature New Biology 239: 98-101.

GIERER, A. and MEINHARDT, H. (1972). A theory of biological pattern formation. Kybernetik 12: 30-39.

GRENS, A., GEE, L., FISHER, D.A. and BODE, H.R. (1996). Cnnk-2, an nk-2 homeobox gene, has a role in patterning the basal end of the axis in hydra. Dev. Biol. 180: 473-488.

GUdER, C., PHILIPP, I., LENGFELD, T., WATANABE, H., HOBMAYER, B. and HOLSTEIN, T.W. (2006a). The Wnt code: Cnidarians signal the way. Oncogene 25: 7450-7460.

GUDER, C., PINHO, S., NACAK, T.G., SCHMIDT, H.A., HOBMAYER, B., NIEHRS, C. and HOLSTEIN, T.W. (2006b). An ancient Wnt-Dickkopf antagonism in hydra. Development 133: 901-911.

GURLEY, K.A., ELLIOTT, S.A., SIMAKOV, O., SCHMIDT, H.A., HOLSTEIN, T.W. and SANCHEZ ALVARADO, A. (2010). Expression of secreted Wnt pathway components reveals unexpected complexity of the planarian amputation response. Dev Biol 347: 24-39.

HARTERINK, M., KIM, D.H., MIDDELKOOP, T.C., DOAN, T.D., VAN OUDENAARDEN, A. and KORSWAGEN, H.C. (2011). Neuroblast migration along the anteroposterior axis of $C$. elegans is controlled by opposing gradients of Wnts and a secreted Frizzled-related protein. Development 138: 2915-2924.

HASSEL, M. and BERKING, S. (1990). Lithium ions interfere with pattern control in Hydra vulgaris. Roux's Archives 198: 382-388. 
HICKLIN, J., HORNBRUCH, A., WOLPERT, L. and CLARKE, M. (1973). Positional information and pattern regulation in hydra: the formation of boundary regions following axial grafts. J. Embryol. exp. Morphol. 30: 701-725.

HOBMAYER, B., RENTZSCH, F., KUHN, K., HAPPEL, C.M., CRAMER VON LAUE, C., SNYDER, P., ROTHBACHER, U. and HOLSTEIN, T.W. (2000). Wht signalling molecules act in axis formation in the diploblastic metazoan hydra. Nature 407: 186-189.

HOLSTEIN, T.W., HOBMAYER, E. and TECHNAU, U. (2003). Cnidarians: an evolutionarily conserved model system for regeneration?. Dev. Dynamics 226: 257-267.

HÖRSTADIUS, S. and WOLSKY, A. (1936). Studies on determination of bilateral symmetry of the young sea urchin egg. W. Roux'Arch f. Entwicklungsmechanik 135: 69-113.

HUANG, X., DONG, Y. and ZHAO, J. (2004). HetRhomodimer is a DNA-binding protein required for heterocyst differentiation, and the DNA-binding activity is inhibited by PatS. Proc. Natl. Acad. Sci. USA 101: 4848-4853.

INGHAM, P. and HIDALGO, A. (1993). Regulation of wingless transcription in the Drosophila embryo. Development 117: 283-291.

KAMM, K., SCHIERWATER, B., JAKOB, W., DELLAPORTA, S.L. and MILLER, D.J. (2006). Axial patterning and diversification in the Cnidaria predate the HOX system. Curr Biol, 16: 920-926.

KIECKER, C. and NIEHRS, C. (2001). A morphogen gradient of Wnt? $\beta$-catenin signalling regulates anteroposterior neural patterning in Xenopus. Development 128:4189-4201.

KUSSEROW, A., PANG, K., STURM, C., HROUDA, M., LENTFER, J., SCHMIDT, H.A., TECHNAU, U., HAESELER, A.V., HOBMAYER, B., MARTINDALE, M.Q. and HOLSTEIN, T.W. (2005). Unexpected complexity of the Wntgene family in a sea anemone. Nature 433: 156-160.

LEE, H.H. and FRASCH, M. (2000). Wingless effects mesoderm patterning and ectoderm segmentation events via induction of its downstream target sloppy paired. Development 127: 5497-5508.

LEE, S.S., GAFFNEY, E.A. and MONK, N.A.M. (2010). The influence of gene expression time delays on Gierer-Meinhardt pattern formation systems. Bulletin Math. Biol. 72 : 2139-2160.

LENGFELD, T., WATANABLE, H., SIMAKOV, O., LINDGENS, L., GEE, L., LAW, L., SCHMIDT, H.A., OZBEK, S., BODE, H. and HOLSTEIN, T.W. (2009). Multiple Wnts are involved in Hydra organizer formation and regeneration. Dev. Biol. 330: 186-199.

LENHOFF, H. (1991). Ethel Browne, Hans Spemann, and the discovery of the organizer phemenon. Biol. Bull. 181: 72-80.

LORENOWICZ, M.J. and KORSWAGEN, H.C. (2009). Sailing with the Wnt charting the Wnt processing and secretion route. Exp. Cell Res. 315: 2683-2689.

MAO, B., WU, W., LI, Y., HOPPE, D., STANNEK, P., GLINKA, A. and NIEHRS, C. (2001). LDL-receptor-related protein 6is a receptor for Dickkopfproteins. Nature 411:321-325.

MARJORAM, L. and WRIGHT, C. (2011). Rapid differential transport of Nodal and Lefty on sulfated proteoglycan-rich extracellular matrix regulates left-right asymmetry in Xenopus. Development 138: 475-485.

MARTIN, B.L. and KIMELMAN, D. (2009). Wnt signaling and the evolution of embryonic posterior development. Curr Biol 19: R215-R219.

MARTINEZ, D.E., DIRKSEN, M.L., BODE, P.M., JAMRICH, M., STEELE, R.E. and BODE, H.R. (1997). Budhead, a forkhead hnf-3 homolog, is expressed during axis formation and head specification in hydra. Dev. Biol. 192: 523-536.

MEINHARDT, H. (1982). Models of biological pattern formation. Academic Press, London (available for download at $h$ ttp://www.eb.tuebingen.mpg.de/meinhardt).

MEINHARDT, H. (1989). Models for positional signalling with application to the dorsoventral patterning of insects and segregation into different cell types. Development (Supplement 1989): 169-180.

MEINHARDT, H. (1993). A model for pattern-formation of hypostome, tentacles, and foot in hydra: how to form structures close to each other, how to form them at a distance. Dev. Biol. 157: 321-333.

MEINHARDT, H. (2002). The radial-symmetric hydra and the evolution of the bilateral body plan: an old body became a young brain. Bioessays 24: 185-191.

MEINHARDT, H. (2004). Different strategies for midline formation in bilaterians. Nat Rev Neurosci 5: 502-510.

MEINHARDT, H. (2006). Primary body axes of vertebrates: generation of a near-Cartesian coordinate system and the role of Spemann-type organizer. Dev Dyn. 235:2907-2919.

MEINHARDT, H. (2008). Models of biological pattern formation: from elementary steps to the organization of embryonic axes. Curr. Top. Dev. Biol. 81: 1-63.
MEINHARDT, H. and GIERER, A. (1974). Applications of a theory of biological pattern formation based on lateral inhibition. J. Cell Sci. 15, 321-346

MEINHARDT, H. and GIERER, A. (1974). Applications of a theory of biological pattern formation based on lateral inhibition. J. Cell Sci. 15: 321-346.

MEINHARDT, H. and GIERER, A. (1980). Generation and regeneration of sequences of structures during morphogenesis. J. theor. Biol. 85: 429-450.

MEINHARDT, H. (2012). Turing's theory of morphogenesis of 1952 and the subsequent discovery of the crucial role of local self-enhancement and long-range inhibition. Interface Focus (doi: 10.1098/rsfs.2011.0097).

MÜLLER, W.A. (1989). Diacylglycerol-induced multihead formation in hydra. Development, 105: 309-316.

MÜLLER, W.A. (1995). Competition for factors and cellular resources as a principle of pattern-formation in hydra. 2. Assistance of foot formation by heads and buds and a new model of pattern control. Dev. Biol. 167: 175-189.

MÜLLER, W.A. and PLICKERT, G. (1982). Quantitaitve analysis of an inhibitory gradient field in the hydrozoan stolon. Wilhelm Roux Arch. 191: 56-63.

MÜNDER, S., KÄSBAUER, T., PREXL, A., AUFSCHNAITER, R., ZHANG, X., TOWB, P. and BÖTTGER, A. (2010). Notch signalling defines critical boundary during budding in Hydra. Dev. Biol. 344: 331-345.

NAKAMURA, T., MINE, N., NAKAGUCHI,E., MOCHIZUKI,A., YAMAMOTO, M., YASHIRO, K., MENO, C. and HAMADA, M. (2006). Generation of robust left-right asymmetry in the mouse embryo requires a self-enhancement and lateral-inhibition system. Dev. Cell 11:495-504.

NAKAMURA, Y., TSIAIRIS, C.D., OZBEK, S. and HOLSTEIN, T.W. (2011). Autoregulatory and repressive inputs localize hydra Wnt3 to the head organizer. Proc. Natl. Acad. Sci. USA 108: 9137-9142.

NIEHRS, C. (2004). Regionally specific induction by the Spemann-Mangold organizer. Nat Rev Genet 5: 425-434.

NIEHRS, C. (2006). Function and biological roles of the Dickkopf family of Wnt modulators. Oncogene 25: 7469-7481.

PHILIPP, I., AUFSCHNAITER, R., OZBEK, S., PONTASCH, S., JENEWEIN, M. WATANABE, H., RENTZSCH, F., HOLSTEIN, T.W. and HOBMAYER, B. (2009). $W n t / \beta$-catenin and noncanonical $W n t$ signaling interact in tissue evagination in the simple eumetazoan hydra. Proc. Natl. Acad. Sci. USA 106: 4290-4295.

PLICKERT, G. (1980). Mechanically induced stolon branching in Eirene viridula (Thecata, Campanulinidae). "Developmental and Cellular Biology of Coelenterates" (P. Tardent and R. Tardent, eds). Elsevier/North-Hollland Biomedical Press, Amsterdam, New York, Oxford.

PLICKERT, P., JACOBY, V., FRANK, U., MÜLLER, W.A. and MOKADY, O. (2006). Wnt signaling in hydroid development: Formation of the primary body axis inembryogenesis and its subsequent patterning. Dev. Biol. 298: 368-378.

PORT, F. and BASLER, K. (2010). Wnt trafficking: new insights into Wnt maturation, secretion and spreading. Traffic 11: 1265-1271.

REINHARDT, B., BROUN, M., BLITZ, I.L. and BODE, H.R. (2004). HyBmp5-8b, a Bmp58 orthologue, acts during axial patterning and tentacle formation in hydra. Dev Biol 267: 43-59.

RENTZSCH, F., FRITZENWANKER, J.H., JENS, H., SCHOLZ, C.B. and TECHNAU, U. (2008). FGF signalling controls formation of the apical sensory organ in the Cnidarian Nematostella vectensis. Development 135: 1761-1769.

RISSER, D.D. and CALLAHAN, S.M. (2009). Genetic and cytological evidence that heterocyst patterning is regulated by inhibitor gradients that promote activator decay. Proc. Natl. Acad. Sci. USA 106: 19884-19888.

SAKUMA, R., OHNISHI, Y., MENO, C., FUJII, H., JUAN, H., TAKEUCHI, J., OGURA, T., LI, E., MIYAZONO, K. and HAMADA, H. (2002). Inhibition of Nodal signalling by Lefty mediated through interaction with common receptors and efficient diffusion. Genes Cells 7: 401-412.

SHIMIZU, H. (2012). Transplantation analysis of developmental mechanisms in Hydra. Int J Dev Biol 56: 463-472.

SHIMIZU, H. and FUJISAWA, T. (2003). Peduncle of Hydra and the heart of higher organisms share a common ancestral origin. Genesis 36: 182-186.

SHOSTAK, S. (1973). The complexity of hydra: homeostasis, morphogenesis, controls and integration. Quart. Rev. Biol. 49: 287-310.

SMITH, K.M., GEE, L. and BODE, H.R. (2000). Hyalx, an aristaless-related gene, is involved in tentacle formation in hydra. Development 127: 4743-4752.

TECHNAU, U. and BODE, H.R. (1999). HyBra1, a Brachyury homologue, acts during 
head formation in hydra. Development 126: 999-1010.

TECHNAU, U., CRAMER VON LAUE, C., RENTZSCH, F., LUFT, S., HOBMAYER, B., BODE, H.R. and HOLSTEIN, T.W. (2000). Parameters of self-organization in Hydra aggregates. Proc. Natl. Acad. Sci. USA 97: 12127-12131.

TECHNAU, U. and HOLSTEIN, T.W. (1995). Head formation in hydra is different at apical and basal levels. Development 121: 1273-1282.

TONISSEN, K.F., DRYSDALE, T.A., LINTS, T.J., HARVEY, R.P. and KRIEG, P.A. (1994). $X N k x-2.5$, a Xenopus gene related to $N k x-2.5$ and tinman: evidence for a conserved role in cardiac development. Dev. Biol., 192: 325-328.

TREMBLEY, A. (1744). Memoires pour servir a l'histoire d'un genre de polypes d'eau douce. J. u. H. Verbeek, Leiden.

TURING, A. (1952). The chemical basis of morphogenesis. Phil. Trans. B. 237: 37-72.
WACKER, S.A., JANSEN, H.J., MCNULTY, C.L., HOUTZAGER, E. and DURSTON, A.J. (2004). Timed interactions between the Hox expressing non-organiser mesoderm and the Spemann organiser generate positional information during vertebrate gastrulation. Dev. Biol. 268: 207-219.

WILBY, O.K. and WEBSTER, G. (1970a). Studies on the transmission of hypostome inhibition in hydra. J. Embryol. exp. Morphol. 24: 583-593.

WILBY, O.K. and WEBSTER, G. (1970b). Experimental studies on axial polarity in hydra. J. Embryol. exp. Morphol. 24: 595-613.

WOLPERT, L., HICKLIN, J. and HORNBRUCH, A. (1971). Positional information and pattern regulation in regeneration of hydra. Symp. Soc. exp. Biol. 25: 391-415.

WURST, W. and BALLY-CUIF, L. (2001). Neural plate patterning:Upstream and downstream of the istmic organizer. Nature Rev. Neurosci. 2: 99-108.

\section{Further Related Reading, published previously in the Int. J. Dev. Biol.}

Planarian regeneration: achievements and future directions after 20 years of research. Emili Saló, Josep F. Abril, Teresa Adell, Francesc Cebriá, Kay Eckelt, Enrique FernándezTaboada, Mette Handberg-Thorsager, Marta Iglesias, M Dolores Molina and Gustavo Rodríguez-Esteban

Int. J. Dev. Biol. (2009) 53: 1317-1327

From Planarians to Mammals - the many faces of regeneration.

Jerzy Moraczewski, Karolina Archacka, Edyta Brzoska, Maria-Anna Ciemerych, Iwona Grabowska, Katarzyna Janczyk-Ilach, Wladyslawa Streminska and Malgorzata Zimowska Int. J. Dev. Biol. (2008) 52: 219-227

Compartments in scyphozoa.

Berking, S. and Herrmann, K.

Int J Dev Biol (2007) 51: 221-228

Wnt signaling in hydroid development: ectopic heads and giant buds induced by GSK3beta inhibitors.

Werner Müller, Uri Frank, Regina Teo, Ofer Mokady, Christina Guette and Günter Plickert Int. J. Dev. Biol. (2007) 51: 211-220

Patterning a multi-headed mutant in Hydractinia: enhancement of head formation and its phenotypic normalization.

Werner A Müller, Regina Teo and Frank Möhrlen

Int. J. Dev. Biol. (2004) 48: 9-15

Pattern regulation properties of a Hydra strain which produces additional heads along the body axis.

S Zeretzke and S Berking

Int. J. Dev. Biol. (2001) 45: 431-439

Organizer and axes formation as a self-organizing process.

Meinhardt, $\mathrm{H}$.

Int. J. Dev. Biol. (2001) 45: 177-188

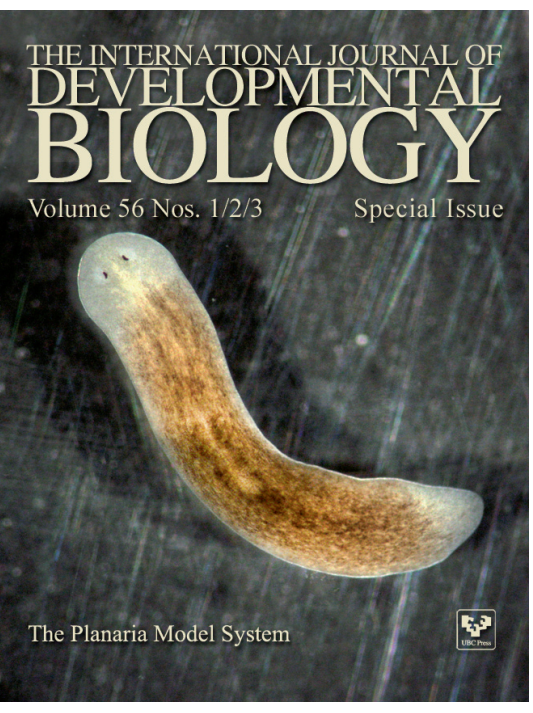

5 yr ISI Impact Factor $(2010)=2.961$

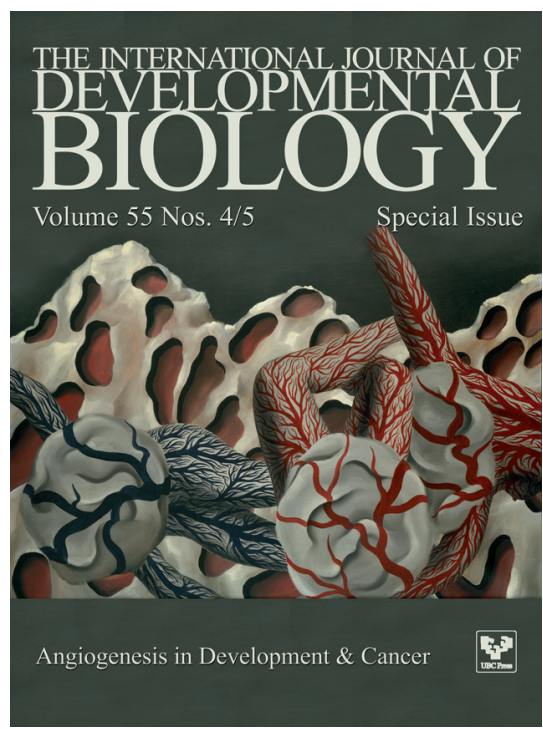

